\title{
DETECTING A PROBIOTIC PRODUCT WITHIN THE GUT OF BROILER CHICKENS
}

\author{
A Thesis \\ presented to \\ the Faculty of California Polytechnic State University, \\ San Luis Obispo
}

\author{
In Partial Fulfillment \\ of the Requirements for the Degree \\ Master of Science in Biology
}

by

Anneka Pisula

August 2018 
(C) 2018

Anneka Pisula

ALL RIGHTS RESERVED 
TITLE: Detecting a Probiotic Product Within the Gut of Broiler Chickens

AUTHOR: Anneka Pisula

DATE SUBMITTED: August 2018

COMMITTEE CHAIR: Christopher L. Kitts, Ph.D.

Professor of Biological Sciences

COMMITTEE MEMBER: Michael Black, Ph.D.

Professor of Biological Sciences

COMMITTEE MEMBER: $\quad$ Darin C. Bennett, Ph.D.

Professor of Animal Science 


\section{ABSTRACT \\ Detecting a Probiotic Product Within the Gut of Broiler Chickens}

Anneka Pisula

As of January 2017, the U.S. poultry industry banned the use of antibiotics and now relies on alternatives such as probiotics to help protect animal health. Although probiotic use is not a new concept in the poultry industry, identifying the best combination of bacterial strains to generate an effective probiotic formula requires further investigation. This study aimed to detect a probiotic product of four bacterial strains (Pedioccoccus acidilactici, Pediococcus pentosaceus, Lactobacillus plantarum, and Bacillus subtilis) in a feeding trial with broiler chickens. Birds given the probiotic were predicted to show an improved growth performance with the probiotics colonizing the gut. Ninety-six broiler chickens were equally divided into 3 treatment and 3 control pens. During the 25-day experiment, birds were fed a starter diet (days 0-11) and a grower diet (days 12-25). Experimental birds were administered the probiotic product via the drinking water at a concentration of $3.1 \times 10^{4} \mathrm{CFU} / \mathrm{ml}$. Control birds had an equivalent amount of dextrose filler added to their water supply. Feces were collected hourly on day one and daily thereafter. On days 1, 22, and 25 of the experiment, 2 birds from each pen were euthanized for gut sampling. Lumen and mucosa samples were collected from the duodenum, jejunum, ileum, and ceca. Species-specific and strain specific PCR primers were employed for probiotic detection. Wild strains of $P$. acidilactici, $P$. pentosaceus, and $L$. plantarum were detected in the feeds, inhibiting detection of the probiotic strains when using species-specific PCR primers. Strain-specific primers were used to detect the probiotic Pedioccoccus acidilactici and Lactobacillus plantarum strains. B. subtilis was detected in feces within one hour of probiotic administration and was predominantly detected in experimental birds only. Both $P$. acidilactici and L. plantarum probiotic strains were initially detected in the feces of treated birds within two hours of probiotic administration and again ten days later. Both L. plantarum and B. subtilis were seen only in treated bird gut samples. L. plantarum was predominantly detected in the ceca near the end of the small intestine. $P$. pentosaceus was observed more often in treated gut samples and $P$. acidilactici $i$ was the least commonly detected probiotic strain. All administered bacteria were rarely seen in mucosa samples. Feed-endogenous $P$. acidilactici and $L$. plantarum strains became progressively more detectable in the mucosa along the gastrointestinal tract suggesting gut colonization, however, probiotic strains did not appear to colonize the mucosa of treated birds. Although probiotic strains were no longer detected after product removal, all probiotic strains were detected in feces and gut samples during probiotic administration, suggesting the bacteria can colonize the gut. Probiotic supplementation did not result in significant differences in body weight gain, feed intake, or feed conversion ratio. However, birds growing in a more stressful environment than the carefully controlled experimental set up used here may show probiotic-related effects. This study identified that the probiotic bacteria appeared to survive the gastrointestinal tract, exhibited a transit time of 1-2 hours, could possibly colonize chickens, and localized near the end of the chicken gut. 


\section{ACKNOWLEDGMENTS}

First, I would like to thank the probiotic company for their funding, partnership, and the opportunity to perform this work. The probiotic industry collaborators also provided access to Cal Poly's Center for Applications in Biotechnology (CAB), which is greatly appreciated. Funding for the animal trial was provided by the California State University Agricultural Research Institute (Bennett, DC, Peterson DG. Role of the gastrointestinal microbiota in poultry production: probiotics as an alternative to the use of antibiotics).

A special thank you goes to Dr. Jennifer VanderKelen, the creator of the probiotic strain and species-specific primers used in this study. Your years of hard work and dedication made my project possible, and I am eternally grateful. Also, you offered me immediate help throughout the project's entirety whenever it was needed, and I greatly appreciate all your contributions.

I sincerely acknowledge my committee member, Dr. Darin Bennett, for his broiler chicken expertise and mentorship. Your passionate interest in this research and critical input not only allowed a successful probiotic feeding trial but expanded my poultry knowledge immensely. I thank you for your dedication to this study and performance of gut dissections. Also, thanks to you and Steve Soderstrom, the Poultry Center Manager, I was conveniently able to house the study chickens at the California Polytechnic State University Poultry Unit.

I would like to acknowledge my wonderful research team of undergraduates: Konor Niles von Kraut, Taylor Cates, Ashley Bruce, Bethany Porta, Carson Wack, Julia Armanino, and Davin Galamay for all their support and assistance. I especially appreciate Konor Niles von Kraut and Taylor Cates who both dedicated long hours at the poultry unit and in the CAB Lab. I commend you both for your diligent work ethic and commitment to this study.

I thank my family for their endless support and continuous encouragement that enables my continued success. You always assured confidence in me that I can achieve greatness even during stressful times. My family also inspired an important motto in me, "play is the highest form of research"- Albert Einstein. And to my fellow graduate cohort, thank you for your wonderful friendship and making this journey enjoyable.

Last, but certainly not least, to my advisor and committee chair, Dr. Christopher L. Kitts, your guidance and mentorship over the last few years is appreciated immensely. I constantly faced challenges along the way and you always steered me in the right direction. I have learned such a great deal and I am extremely grateful for this wonderful experience as a young scientist. 


\section{TABLE OF CONTENTS}

Page

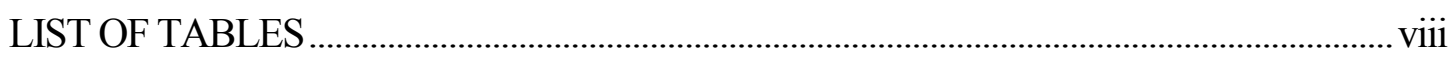

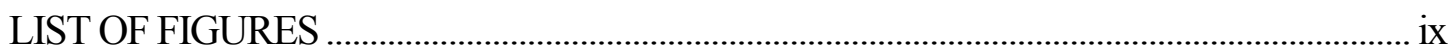

CHAPTER

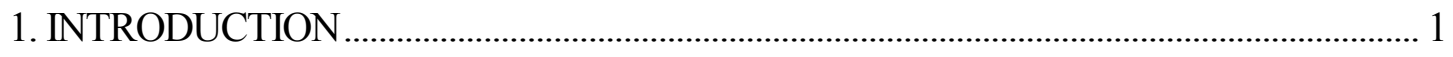

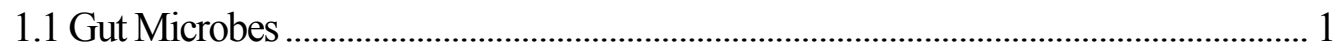

1.2 Chicken Gut Colonization ............................................................................................. 3

1.3 Poultry Industry Ban of Antibiotics and Replacement by Probiotics ........................... 4

1.4 Pediococcus a Potential Probiotic...................................................................

1.5 Testing a New Probiotic Formula ………………...................................6

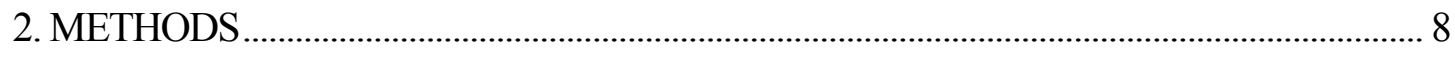

2.1 Ethics Statement........................................................................................................ 8

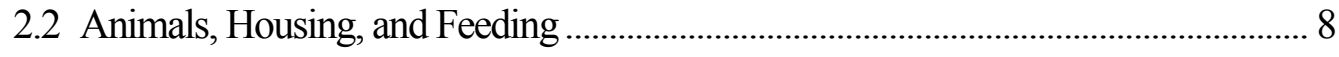

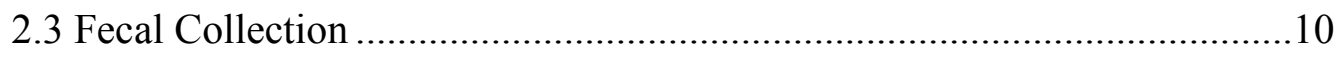

2.4 Collection of Gut Samples ....................................................................11

2.5 Isolation of Fecal Bacterial DNA ....................................................................................... 11

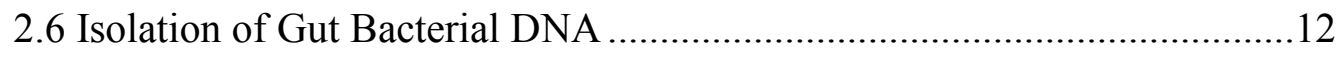

2.7 Probiotic Survival in Poultry Unit Water..................................................13

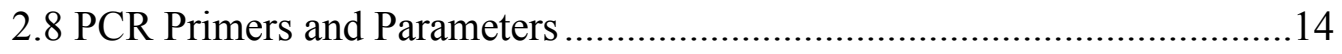

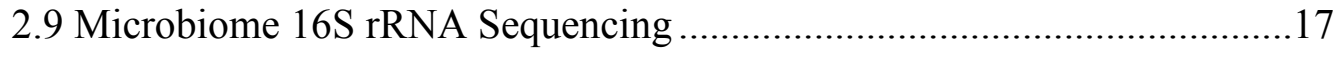

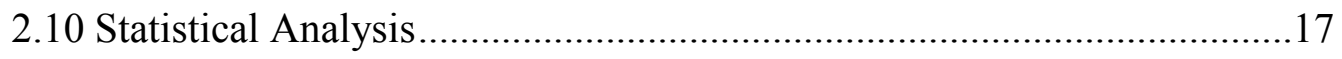

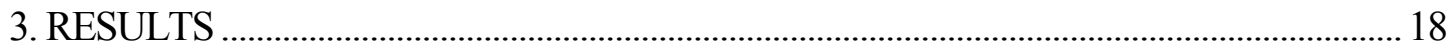




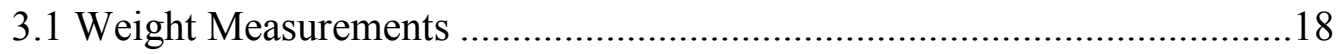

3.2 Probiotic Survival in Poultry Unit Water.......................................................18

3.3 Background Probiotic Bacteria in Feeds...................................................19

3.4 Probiotic Bacteria in Fecal Samples ..........................................................20

3.5 Detection of Probiotic Species Bacteria in Day 1 Gut Samples ..................22

3.6 Probiotic Bacteria in Day 22 Guts Samples..............................................23

3.7 Detection of Probiotic Bacteria in Day 25 Guts .........................................27

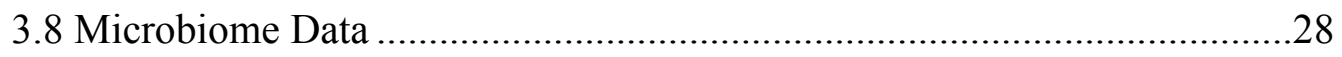

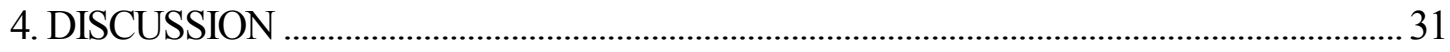

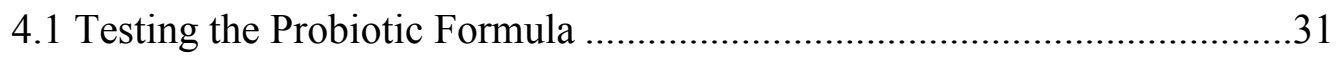

4.2 Low Concentrations of Probiotic Species Near Detection Limit..................31

4.3 Probiotic Bacterial Survival in Poultry Unit Water .....................................32

4.4 Species-Specific Primers Cannot Distinguish Probiotic Strains...................34

4.5 Survival and Transit Time of Probiotic Bacteria................................................................ 34

4.6 Probiotic Bacteria in Competition with Chicken Feed Bacteria ...................36

4.7 Probiotic Bacteria Gut Localization..............................................................37

4.8 Lumen and Mucosa Gut Microbiota ............................................................39

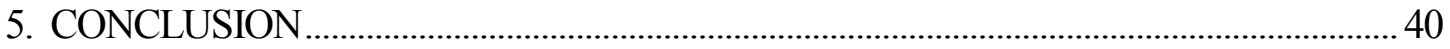

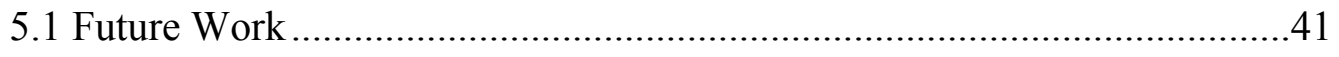

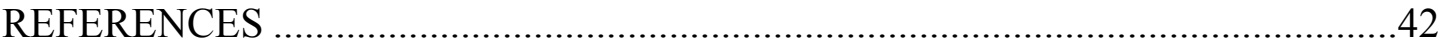




\section{LIST OF TABLES}

Table

1. Ingredients used in the study diets

2. Species-specific primers used for P. pentosaceu and B. subtilis

3. Species and strain specific primers used for P. acidilactici and L. plantarum 16

4. Effects of probiotic supplementation on broiler chicken growth performance. 18

5. Detection and concentrations of probiotic bacteria within the feed using species-specific primers..

6. Concentration of probiotic bacteria in fecal samples using species-specific primers

7. Detection of probiotic bacteria in day 1 gut samples according to bird and pen using species-specific primers

8. Detection of $E$. coli in gut samples

9. Day 22 gut samples genomic DNA concentration (ng/ $\mu \mathrm{l})$.

10. Detecting probiotic bacteria in day 22 gut samples according to bird and pen using both strain and species-specific primers

11. Detection of probiotic bacteria in day 25 gut samples according to bird and pen using both strain and species-specific primers.

12. Number of gut samples producing usable $16 \mathrm{~S}$ sequence data from day $22 \ldots \ldots \ldots . . .28$

13. Microbiome alpha diversity .30 


\section{LIST OF FIGURES}

Figure $\quad$ Page

1. Chicken gut anatomy............................................................................................................. 4

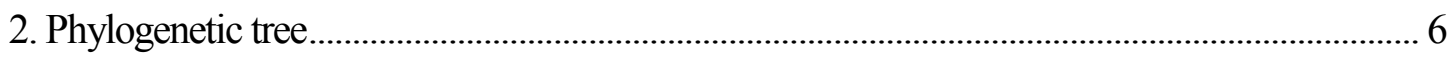

3. Experimental timeline and set up............................................................................................. 9

4. Chicken gut compartments stored separately ...................................................................... 11

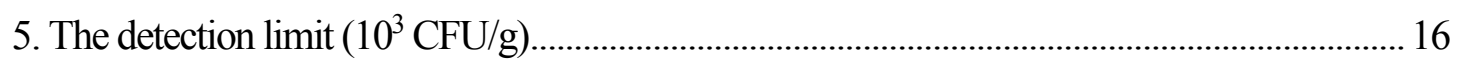

6. PCR detection of probiotic bacteria in the feces using strain and species-specific

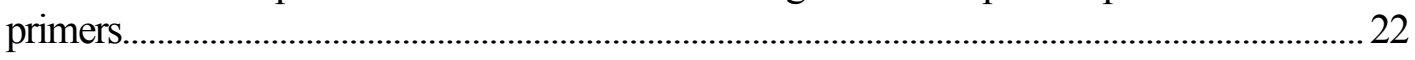

7. Cluster analysis of jejunal lumen and mucosa microbiome data at the family taxonomic

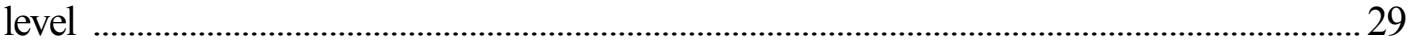

8. Cluster analysis of ileal lumen and mucosa microbiome data at the family taxonomic

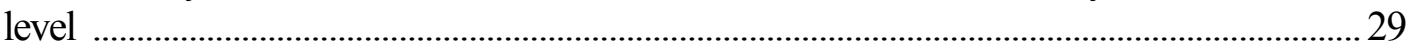

9. Cluster analysis of cecal lumen and mucosa microbiome data at the family taxonomic

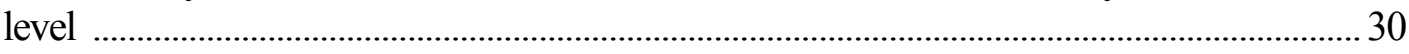




\section{INTRODUCTION}

\subsection{Gut Microbes}

The gastrointestinal tract of birds and mammals serves as a home to several different types of microorganisms such as archaea, fungi, yeasts, and bacteria. In terms of numbers, bacterial cells consisting mainly of members of the Firmicutes and Bacteroidetes groups far outnumber the cells in a host organism (Qin et al., 2010). Each bacterial species has its own niche in the gastrointestinal tract and the bacteria residing inside the small intestine differ from those of the large intestine (Fooks et al., 2002). All these microorganisms live together in a diverse community forming the normal gut flora. The gut is a wonderful environment for hundreds of bacterial species to live and thrive with a constant warm temperature and available nutrients necessary for microbial survival. In return, the intestinal microbiota play a critical role in many aspects of host health, including digestion and immune responses (Turnbaugh et al., 2007).

The gut microbiome is constantly changing in response to diet, host health, and other factors. When the bacterial community changes and/or pathogens increase within the host, the number of beneficial bacterial cells can decrease, and disease states can arise such as autoimmune, cardiovascular, and inflammation disorders as well as colonic cancers (Carding et al., 2015). This increase in the number of pathogenic microorganisms or imbalance in microbial populations is referred to as dysbiosis. Gut dysbiosis causes disruption of normal intestinal barrier function which leads to reduced nutrition and increased vulnerability to infection (Ray et al., 2016; Tang et al., 2017). Ingestion of probiotics contributes to intestinal microbial balance and probiotics can be taken proactively to maintain host organism gut health (Williams, 2010). Probiotics are live microbial feed supplements that benefit the host by improving the normal microflora of 
the gut (Fuller, 1989), used to provide copious amounts of beneficial bacteria to combat infection or dysbiosis. Dead probiotic cells are also considered gut modulators that interact with the gastrointestinal mucosa and appear to offer similar beneficial effects compared to live cells (Adams, 2010; Pedroso et al., 2010). Probiotics produce organic acids, compete for nutrients, and induce immune factors to prevent pathogen growth (Fooks et al., 2002).

Lactobacillus and Bifidobacterium species are most commonly used in commercial probiotic formulas; however, the overall effectiveness of a probiotic supplement varies at the strain level (Gu et al., 2015; Soccol et al., 2010) L. plantarum, L. casei, L. rhamnosus are a few species of Lactobacillus commonly used as probiotic products while B. lactic, B. breve, B. longum, and B. bifidum are important probiotic species of Bifidobacterium (Fijan, 2014). In addition, Bacillus species such as B. subtilis, B. coagulans, and B. cereus have also shown probiotic properties and are being used in commercial probiotic formulas (Casula et al., 2002). Even though the species mentioned above are considered probiotics, it is important to recognize that probiotic formulas differ depending on the combination and composition of bacterial strains arranged together. Each strain, even from the same species, colonize the gastrointestinal tract differently and in response may serve a specific functional role contributing to an overall health benefit that is unique compared to another strain (Williams, 2010; Adams, 2010). Therefore, to create the best supplement, probiotic formulas are designed based on the probiotic properties of individual strains (Santosa at el., 2006). Some commercial probiotic strains that have been studied include: L. plantarum 299v Lp01, L. rhamnosus GG, B. bifidum Bb-1, and B. longum BB536 (Soccol et al., 2010). 


\subsection{Chicken Gut Colonization}

The gastrointestinal tract in broiler chickens is sterile at hatching and bacteria from both the environment and diet immediately colonize the gut (Alloui et al., 2013). However, the development and stabilization of microflora in the small intestine occurs several weeks after hatching (Smirnov et al., 2006). Once the gut is initially colonized by a particular bacterial species it is difficult for other microbes to become established within the community as there is limited habitable space (Cisek et al., 2014). Therefore, supplementation of probiotics during early life is of great importance to the host because many environmental bacteria capable of gut adhesion and withstanding the harsh environmental stresses of the intestines will likely colonize niches in the gastrointestinal tract (Gaggìa et al., 2010; Chichlowski et al., 2007).

Many bacterial species colonize different portions of the chicken intestine (Figure 1) and allow proper digestion and optimal nutrient absorption. The major site of bacterial colonization and microbial fermentation is the ceca whereas the duodenum and the rest of the small intestine harbor relatively low numbers of bacteria (Barnes, 1972). Detecting bacteria in the mucosal layer of the gut after administration of probiotics is one way to determine possible bacterial gut colonization (Donaldson et al., 2016). The colonized bacteria both living and deceased from the small intestine slough off and pass through the gastrointestinal tract expelling out as feces. When gut colonization does not occur, the microorganisms travel through the lumen of the gastrointestinal tract until they are excreted in the feces. However, bacteria degraded during gut passage would not be present in the feces. The amount of time it takes the administered probiotic bacteria to 
successfully survive the harsh environment transiting through the entire gastrointestinal tract and exit in the feces is called transit time.

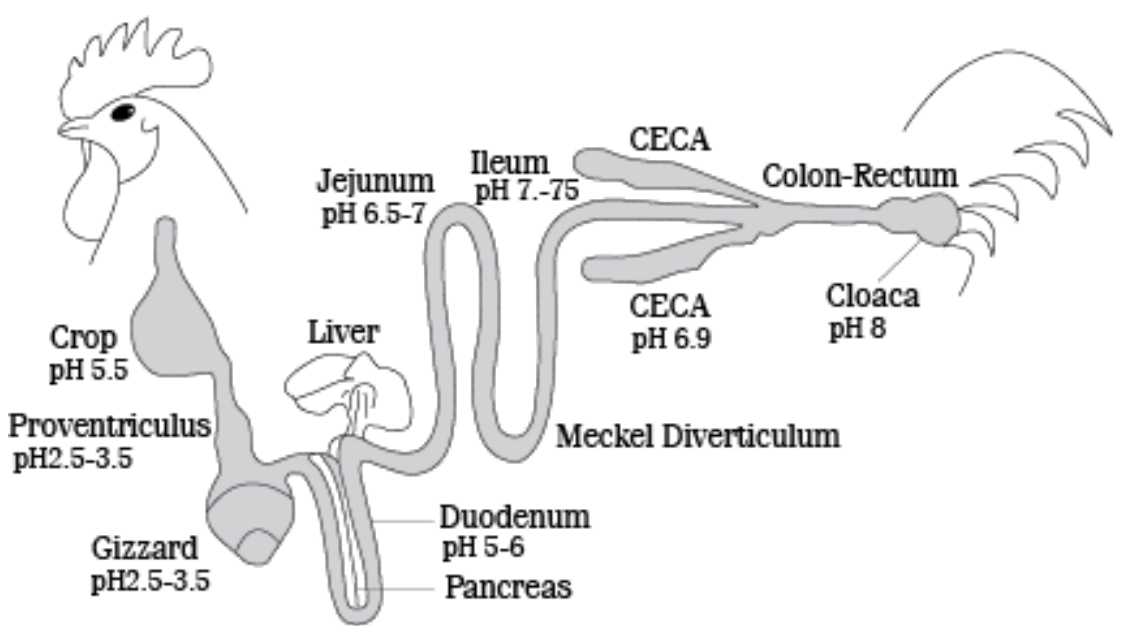

Figure 1: Chicken gut anatomy. The different components of the chicken gut are labeled along with corresponding pHs (Avon Animal Health, 2015).

\subsection{Poultry Industry Ban of Antibiotics and Replacement by Probiotics}

Antibiotics are frequently used in the poultry industry to enhance animal growth and combat infectious diseases caused by pathogens such as Salmonella and Campylobacter (Hughes et al., 2008). However, the agricultural use of antibiotics since the 1940's has contributed to the rising prevalence of antibiotic resistant bacteria (Economou et al., 2015). In 2006, the European Union banned the use of antibiotics in poultry and the industry now administers probiotics (Alloui et al., 2013). The use of probiotics has been recognized as beneficial for over 100 years and specifically used in poultry for 50 years (Vila et al., 2010). Probiotics in commercial poultry applications have shown to improve broiler chicken growth performance such as increases in weight gain and feed efficiency (Gadde et al., 2017; Aliakbarpour et al., 2012; Mountzouris et al., 2010). With an increasing demand for chicken meat as a top protein source for human consumption in the U.S., development of safe alternatives to antibiotics is necessary (Tuohy et al., 2005; 
Ricke et al., 2010). As of January 2017, the U.S. poultry industry banned the use of antibiotics prophylactically and now relies on probiotics (The National Chicken Council, 2015; Geier et al., 2009; Lillehoj et al., 2012). The therapeutic effectiveness of probiotics used in the poultry industry depends on numerous factors such as the microbial species and strain composition, administration regimen and dosage including the method and frequency, diet, bird age, and environmental factors (Mikulski et al., 2012). The most common probiotics typically used in poultry are Lactobacillus spp., Streptococcus faecium, Bacillus spp., and yeasts (Vila et al., 2010). Although probiotic use is not a new concept in the poultry industry, identifying the best combination of bacterial strains to generate an effective probiotic formula requires further investigation.

\subsection{Pediococcus a Potential Probiotic}

Pediococcus species, members of the Lactobacillaceae family, have not been traditionally recognized as common probiotics like Lactobacillus or Bacillus. spp. However, they demonstrate many probiotic characteristics. Pediococcus species can survive in acidic and bile salt conditions, form biofilms, adhere to human epithelial colorectal adenocarcinoma cells, and have antimicrobial activities against common intestinal pathogenic bacteria (Noohi et al., 2016; Erkkilä et al., 2000). Pediococcus species exhibit antagonistic effects against pathogenic microorganisms through the

production of lactic acid, antimicrobial peptides, and proteinaceous toxins (Papagianni et al., 2009). Even though Pediococcus grows optimally in an acidic environment, this species can also be grown in a wide range of temperature, $\mathrm{pH}$, and osmotic pressures, which makes it an ideal candidate for digestive tract colonization. All the above 
information combined suggests that Pediococcus species might have the ability to enhance gut health for both humans and animals.

\subsection{Testing a New Probiotic Formula}

The probiotic formula used in this study consists of strains from four bacterial species:

Pediococcus acidilactici, Pediococcus pentosaceus, Lactobacillus plantarum, and

Bacillus subtilis. The probiotic formula total concentration was $3.1 \times 10^{8} \mathrm{CFU} / \mathrm{g}$ (in a

dextrose carrier), which includes the three lactic strains (P. acidilactici, $P$. pentosaceus,

and L. plantarum) at $10^{8} \mathrm{CFU} / \mathrm{g}$ each and B. subtilis at $10^{7} \mathrm{CFU} / \mathrm{g}$. The lactic acid

producing bacterial strains were selected from a subset of the Lactobacillaceae family, as

shown in Figure 2. The combination of bacteria was created with an intention of both human and animal health applications. The genomes for all four bacterial strains are sequenced and annotated.

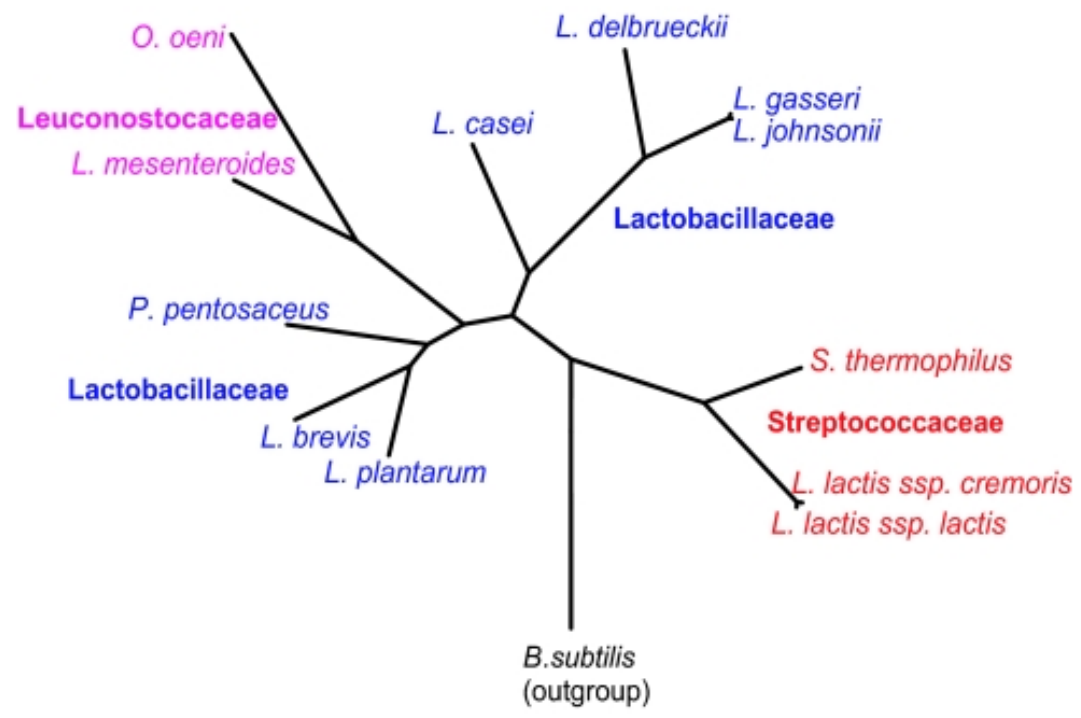

Figure 2: Phylogenetic tree. Lactobacillaceae portion of the phylogenetic tree shows the branches of the bacterial species composing the probiotic formula used in this study: $P$. pentosaceus, L. plantarum, and P. acidilactici (P. acidilactici not displayed on figure, however, branch would be near $P$. pentosaceus) are closely related compared to B. subtilis which is labeled as an outgroup (Makarova at el., 2006). 
This newly developed probiotic formula has potential use in commercial applications to improve broiler chicken health, increase productivity in the poultry industry, and aid public concerns regarding antibiotic pathogenic resistance. The probiotic formula was hypothesized to withstand the acidic environment of the broiler chicken gut, colonize the ceca, exhibit a detectable transit time to the feces, and display an overall contribution to improved growth performance of broiler chickens.

This study investigated probiotic transit time, gut colonization, and localization within broiler chickens. The lumen contents and mucosal layer of the duodenum, jejunum, ileum, and ceca were analyzed to identify localization and possible bacterial colonization within the small intestine and ceca. If no colonization occurred, administered probiotic bacteria were predicted to at least be detectable in the lumen compartments of the gut as well as the feces. After probiotic administration, bacteria were predicted to travel through the gastrointestinal tract as intact cells to the feces, indicating survival of the digestive process and potential capability for gut colonization. The probiotic bacteria were expected to have a transit time of a couple hours based on chicken diet passage rates (Sturkie, 1976). Last, broiler chickens fed probiotics were predicted to exhibit increased weight gain. 


\section{METHODS}

\subsection{Ethics Statement}

The probiotic feeding trial regarding animal research was approved by and followed California Polytechnic State University IACUC 1613. Animal care and management practices were performed for animal wellbeing.

\subsection{Animals, Housing, and Feeding}

Ninety-six male and female broiler chicks (Ross 708) were delivered from the Foster Farms hatchery (Livingston, CA) to the California Polytechnic State University Poultry Unit. Upon delivery, the chicks were spray vaccinated and individually weighed. Female and male birds were housed together for the duration of the study. Sixteen chicks were evenly distributed (based on total pen weight) into 6 metal Peterzim brooder unit pens held $80 \mathrm{~cm}$ above the ground. Each pen had a metal roof, wire flooring, and both water and feed troughs. The birds received natural daylight and an additional 12 hours of lighting. The housing was arranged to take the different measurements during the study. Forty-eight birds were randomly assigned to either treatment pens (1-3) or control pens (4-6) (Figure 3). 

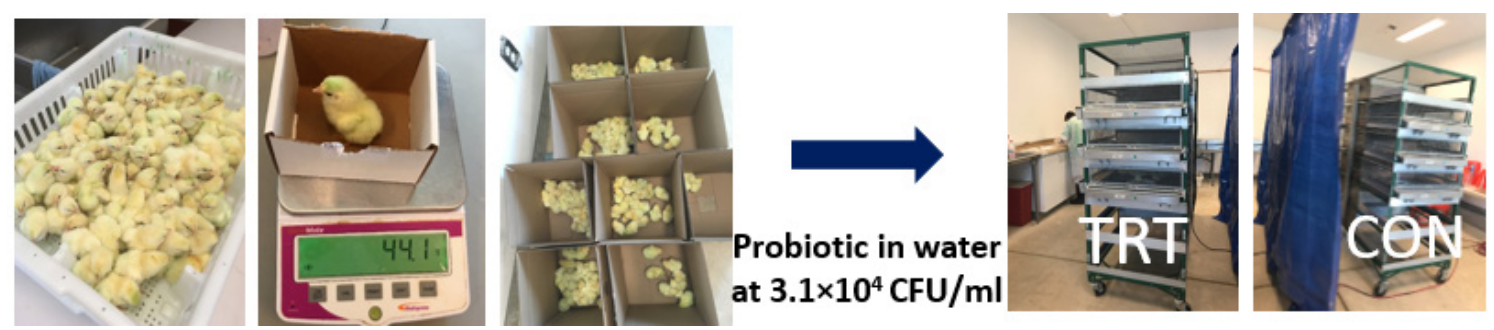

$\widehat{\Lambda}=$ gut sampling

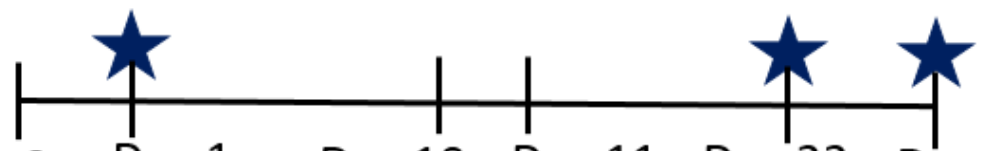

Day 0 Day 1 Day 10 Day 11 Day 22 Day 25

Diet \#1 Probiotic 2x Water Diet \#2 Probiotic

start

stop

Figure 3: Experimental timeline and set up. Experimental timeline from start to stop includes probiotic administration, diet switch, water changes, and gut sampling. The stars represent gut sampling days. Photographs of experimental set up consist of bird arrival, birds individually weighed, and birds separated into weight boxes. The Petersime brooder units labeled TRT correspond to treatment pens (1-3) and CON control pens (4-6).

The chicks received one day (day 0 ) to settle into the housing and their heads were dipped in the drinking water to learn water trough location. The chicks were fed a commercial starter diet during days 0-11 (diet \#1) containing corn, soybean meal, vitamins and minerals. The birds were then switched to a grower diet for days 11-25 (diet \#2) with an increase in corn, decrease in soybean meal, and addition of dried corn distillers' grains, vitamins and minerals (Table 1). Administration of the probiotics (in a dextrose carrier) was initiated on day 1 for a trial of 22 days in the drinking water at a concentration of $3.1 \times 10^{4} \mathrm{CFU} / \mathrm{ml}$ (requested by the probiotic company) to the treated pens. The control birds received water plus dextrose at the same concentration $(0.11 \mathrm{~g} / \mathrm{L})$. The water for both groups was changed daily for the first 9 days, and then twice a day, morning and evening, for the remainder of the experiment. 
Table 1: Ingredients used in the study diets.

\begin{tabular}{ccc}
\hline Ingredients (\%) & $\begin{array}{c}\text { Starter Diet } \\
\text { (Diet 1) }\end{array}$ & $\begin{array}{c}\text { Grower Diet } \\
\text { (Diet 2) }\end{array}$ \\
\hline Corn & 47.8 & 53.2 \\
Soybean meal & 44.9 & 34.2 \\
Corn DDGS & 0 & 5 \\
Vegetable fat & 2.89 & 3.27 \\
$\begin{array}{c}\text { Amino Acids, Vitamins } \\
\text { and Minerals }\end{array}$ & 4.43 & 4.28 \\
\hline
\end{tabular}

Group size in each pen (initially 16) diminished during the experiment as the birds were removed and euthanized for gut contents. The initial group weights for all 6 pens were approximately the same and the birds in each pen were weighed as a group every week throughout the probiotic trial. On days 1,22 , and 25 , individuals to be euthanized were weighed prior to gut sampling. Body weight and feed intake were measured weekly, and body weight gain and feed conversion ratio (feed intake/ body weight gain) were calculated.

\subsection{Fecal Collection}

On day 1 , immediately following probiotic administration, the feces under each pen were collected every hour for 6 hours. Each pen's collection tray was removed, the feces were scrapped off and homogenized by hand mixing, and a $2 \mathrm{ml}$ Eppendorf tube was filled and stored at $-80^{\circ} \mathrm{C}$ for further analysis. Daily fecal collection occurred in the mornings on days 2-21 and from days 22-25 feces were collected twice daily, morning and evening. 


\subsection{Collection of Gut Samples}

On days 1, 22, and 25, two birds from each pen (six birds from each group) were individually weighed and euthanized by a licensed researcher. The chicken abdomen was opened, and the duodenum, jejunum, ileum, and ceca were collected and stored at $-20^{\circ} \mathrm{C}$ for further analysis. Day 1 gut compartments were small enough to fit into $2 \mathrm{ml}$ Eppendorf tubes while the rest of the gut samples were stored in zip-lock bags. Each gut compartment (duodenum, jejunum, ileum, and ceca) was stored separately (Figure 4).

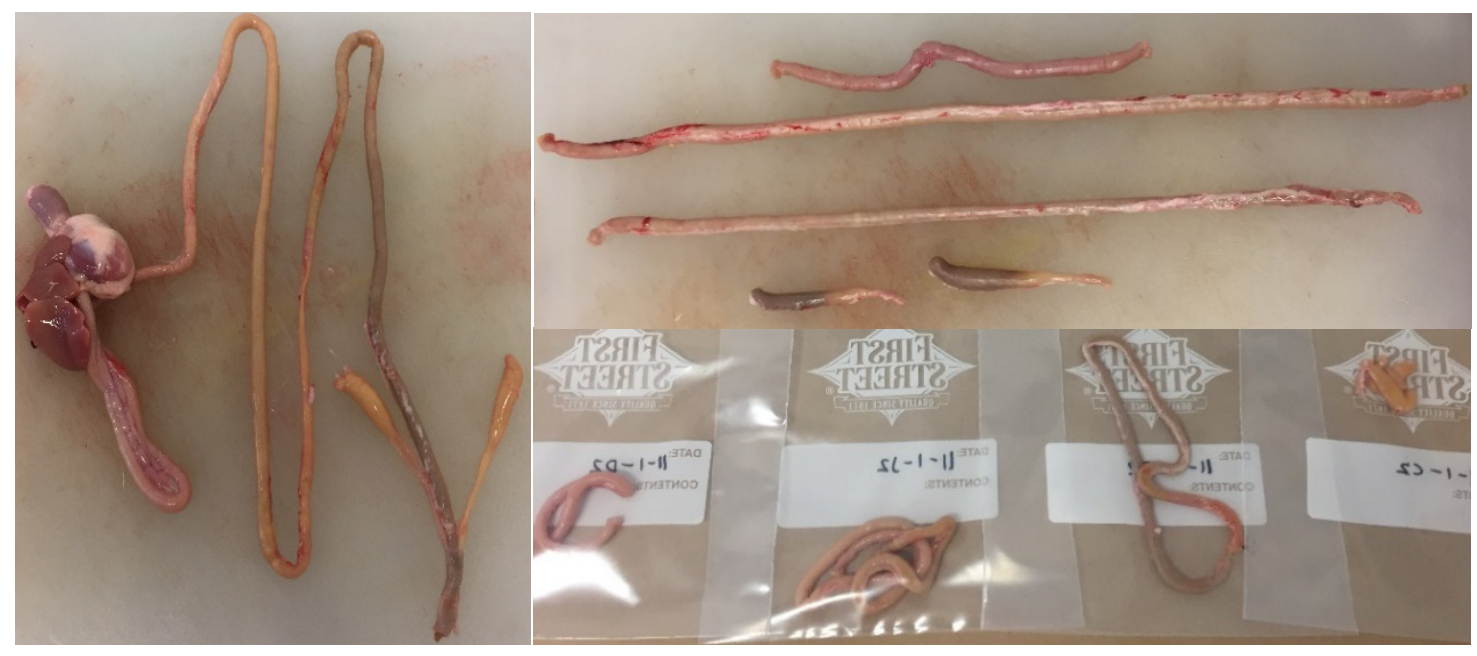

Figure 4: Chicken gut compartments stored separately. All chicken intestines were removed (left picture), each compartment: duodenum, jejunum, ileum, and ceca was separated (top right picture), and stored separately (bottom right picture).

\subsection{Isolation of Fecal Bacterial DNA}

One gram of feces was placed into a $15 \mathrm{ml}$ falcon tube and brought up to $10 \mathrm{ml}$ with $0.1 \%$ peptone, then vortexed well. Then $1 \mathrm{ml}$ was placed into a $1.5 \mathrm{ml}$ Eppendorf tube and centrifuged at $12,000 \mathrm{xg}$ for 15 minutes. The supernatant was removed without disrupting the cell pellet and $750 \mu 1$ of Power Bead Solution of the DNeasy PowerLyzer power soil kit was added to resuspend the cell pellet. The entire solution was transferred to the PowerLyzer bead tube for DNA extraction following PowerLyzer PowerSoil DNA 
Isolation Kit (QIAGEN, Hilden, Germany) protocol with one modification: cell lysis was performed with 3 homogenizations at $6.5 \mathrm{~ms}$ for $45 \mathrm{~s}$ using a Fast Prep FP120 beadbeater (MP Biomedicals, Santa Ana, CA). DNA was quantified using a Molecular Devices Specta Drop micro volume microplate (24 well MVMP) where $2 \mu 1$ of DNA was added per well with a $2 \mu 1$ top cover slide (0.5MM) placed on top (Molecular Devices LLC., Sunnyvale, CA).

\subsection{Isolation of Gut Bacterial DNA}

The day 1 gut samples stored in $2 \mathrm{ml}$ Eppendorf tubes were thawed on ice and then the gut compartment was longitudinally cut open to expose the inside. The entire gut section was placed directly into the bead tube and followed the protocol of the PowerLyzer PowerSoil DNA Isolation Kit with the homogenization modification mentioned above.

The day 22 and day 25 gut samples stored in zip-lock bags were removed from the freezer and thawed manually. After an incision was made at one end of the gut sample, 1 gram of lumen material was squeezed into a $15 \mathrm{ml}$ Falcon tube and brought up to $10 \mathrm{ml}$ with $0.1 \%$ peptone, then vortexed well. One $\mathrm{ml}$ was placed into a $1.5 \mathrm{ml}$ Eppendorf tube and centrifuged at 12,000 x g (13.4 x $1000 \mathrm{rpm})$ for 15 minutes. The supernatant was removed without disrupting the cell pellet and $750 \mu \mathrm{l}$ of Power Bead Solution of the DNeasy PowerLyzer power soil kit was added to resuspend the cell pellet. The entire solution was transferred to the PowerLyzer bead tube for DNA extraction following PowerLyzer PowerSoil DNA Isolation Kit protocol with the homogenization modification mentioned above. 
After the collection of the lumen sample, any remaining lumen contents were squeezed out, and the collection of the mucosa sample was performed. The lining of the gut was rinsed with $5 \mathrm{ml}$ of $0.1 \%$ peptone using a $5 \mathrm{ml}$ syringe inserted at one end of the gut. After the rinse, the gut was gently squeezed to dispense all the injected peptone. The gut section was then opened longitudinally with scissors and spread open further using a blunt round metal spatula. The lining of the gut was scraped using a metal spatula and 0.1 $\mathrm{g}$ of mucosa was placed directly into the bead tube for DNA extraction following the PowerLyzer PowerSoil DNA Isolation Kit with the homogenization modification mentioned above. Occasionally the ceca contents did not weigh the required $0.1 \mathrm{~g}$ of mucosa in which case the other cecum was dissected to acquire the appropriate amount.

\subsection{Probiotic Survival in Poultry Unit Water}

To test the stability of the probiotic bacteria over time, two $100 \mathrm{ml}$ samples of water were collected from the broiler chicken housing unit at the Cal Poly Poultry Unit. Then 0.011 grams of probiotic formula $\left(3.1 \times 10^{4} \mathrm{CFU} / \mathrm{ml}\right)$ was added to one of the $100 \mathrm{ml}$ water sample and the other was used as a control. Both the probiotic and control water samples were incubated at $26.6^{\circ} \mathrm{C}$ for 24 hours representing the $80^{\circ} \mathrm{F}$ poultry housing environment. Serial dilutions and plating occurred at three incubation time points: 0,6 , and 24 hrs. One $15 \mathrm{ml} \mathrm{Falcon}$ tube labeled $10^{-1}$ was filled with $9 \mathrm{ml}$ of $0.1 \%$ peptone. At 0,6 , and $24 \mathrm{hrs}, 1 \mathrm{ml}$ of the probiotic water sample was added to the $10^{-1}$ labeled tube, and vortexed well. For plating, $100 \mu \mathrm{l}$ from the original probiotic water sample tube and $100 \mu \mathrm{f}$ from the one dilution $\left(10^{-1}\right)$ were plated in duplicate on De Man, Rogosa and Sharpe agar (MRS) (EMD Millipore, Burlington, MA) (a low pH agar that selects for 
lactic acid bacteria) and Plate Count Agar (PCA) (Fisher Scientific, Pittsburg, PA) plates. The PCA plating was performed as pour plates. One hundred $\mu$ from both probiotic and control water samples were placed into empty plates and $15 \mathrm{ml}$ of PCA was added, then swirled gently to mix and let solidify. The lactic probiotic bacteria: P. acidilactici, $P$. pentosaceus, and L. plantarum were plated on MRS while B. subtilis on PCA (pour plates). All plates were incubated at $35^{\circ} \mathrm{C}$.

\subsection{PCR Primers and Parameters}

Strain specific primers were designed across mobile element insertion junctions found in the genomes of $P$. acidilactici and L. plantarum probiotic strains, while species-specific primers were designed to species-specific genomic regions of all probiotic strains $(P$. acidilactici, L. plantarum, P. pentosaceus and B. subtilis) (J. VanderKelen, personal communication, October 2017). All strain or species-specific primers targeted single copy genes. PCR reactions were performed in an Applied Biosystems 2720 Thermo Cycler. Each PCR reaction $(20 \mu 1)$ included the following: $10 \mu 1$ 2x OneTaq QuickLoad Mastermix, each primer $10 \mu \mathrm{M}, 4 \mu \mathrm{l}$ DNA sample, and $4 \mu \mathrm{l}$ water. PCR parameters for species-specific primers were $95^{\circ} \mathrm{C}$ for $5 \mathrm{~min}, 40$ cycles of $30 \mathrm{~s}$ at $95^{\circ} \mathrm{C}, 30 \mathrm{~s}$ at $55^{\circ} \mathrm{C}$, and $30 \mathrm{~s}$ at $68^{\circ} \mathrm{C}$, then a final $5 \mathrm{~min}$ at $68^{\circ} \mathrm{C}$ and hold at $4^{\circ} \mathrm{C}$. P. acidilactici and L. plantarum strain-specific primers used the same PCR parameters as the species-specific primers except the annealing temperature was at $56^{\circ} \mathrm{C}$ instead of $55^{\circ} \mathrm{C}$. The qPCR reactions for $P$.

pentosaceus, L. plantarum, and B. subtilis $(20 \mu \mathrm{l})$ included the following: $10 \mu \mathrm{L}$ TaqMan Universal Master Mix II, each primer $900 \mathrm{nM}$, probe $250 \mathrm{nM}$, and $4 \mu \mathrm{L}$ DNA sample. The differences for $P$. acidilactici mastermix included: forward primer $300 \mathrm{nM}$ and 
reverse primer $900 \mathrm{nM}$ with a probe concentration of $50 \mathrm{nM}$. The qPCR parameters for $P$. pentosaceus and L. plantarum included an activation for $10 \mathrm{~min}$ at $95^{\circ} \mathrm{C}$, then 40 cycles of $15 \mathrm{~s}$ at $95^{\circ} \mathrm{C}, 30 \mathrm{~s}$ at $52^{\circ} \mathrm{C}$, and $60 \mathrm{~s}$ at $57^{\circ} \mathrm{C}$. While P. acidilactici and B. subtilis included an activation for $10 \mathrm{~min}$ at $95^{\circ} \mathrm{C}$, then 40 cycles of $15 \mathrm{~s}$ at $95^{\circ} \mathrm{C}, 30 \mathrm{~s}$ at $55^{\circ} \mathrm{C}$, and $60 \mathrm{~s}$ at $60^{\circ} \mathrm{C}$.

To enumerate probiotic treatment bacteria in feed and fecal samples, standard curves for each bacterial strain were generated based on CFU/g (J. VanderKelen, personal communication, April 2017). Serial dilutions were performed in $0.1 \%$ peptone and DNA extractions followed the protocols as previously described. Standard curve DNA was amplified by qPCR in duplicate and standard curves were generated by plotting the cycle threshold values $\left(\mathrm{C}_{\mathrm{T}}\right)$ by the log of cells (Figure 5 ). The replicates became more variable at $10^{3} \mathrm{CFU} / \mathrm{g}$ thus defining a detection limit $\left(10^{3} \mathrm{CFU} / \mathrm{g}\right)$ (Figure 5). The extraction protocol required 0.1 gram of starting material, and a standard volume of $4 \mu 1$ of DNA for both $\mathrm{qPCR}$ and PCR reactions. With starting material at the detection limit $\left(10^{3} \mathrm{CFU} / \mathrm{g}\right)$ and an extraction efficiency of $10-20 \%$ cell lysis and DNA capture, template presence/absence in $4 \mu \mathrm{l}$ could be random below $10^{3} \mathrm{CFU} / \mathrm{g}$. Therefore, replicates of negative PCR results were conducted throughout the study. E. coli was also used as a positive control to indicate the presence of bacterial DNA in the intestinal tract (Awad et al., 2016). The trpBA.f and trpBA.r primers were used to amplify trpA, a 489 bp product from E. coli (Clermont at el., 2008). 


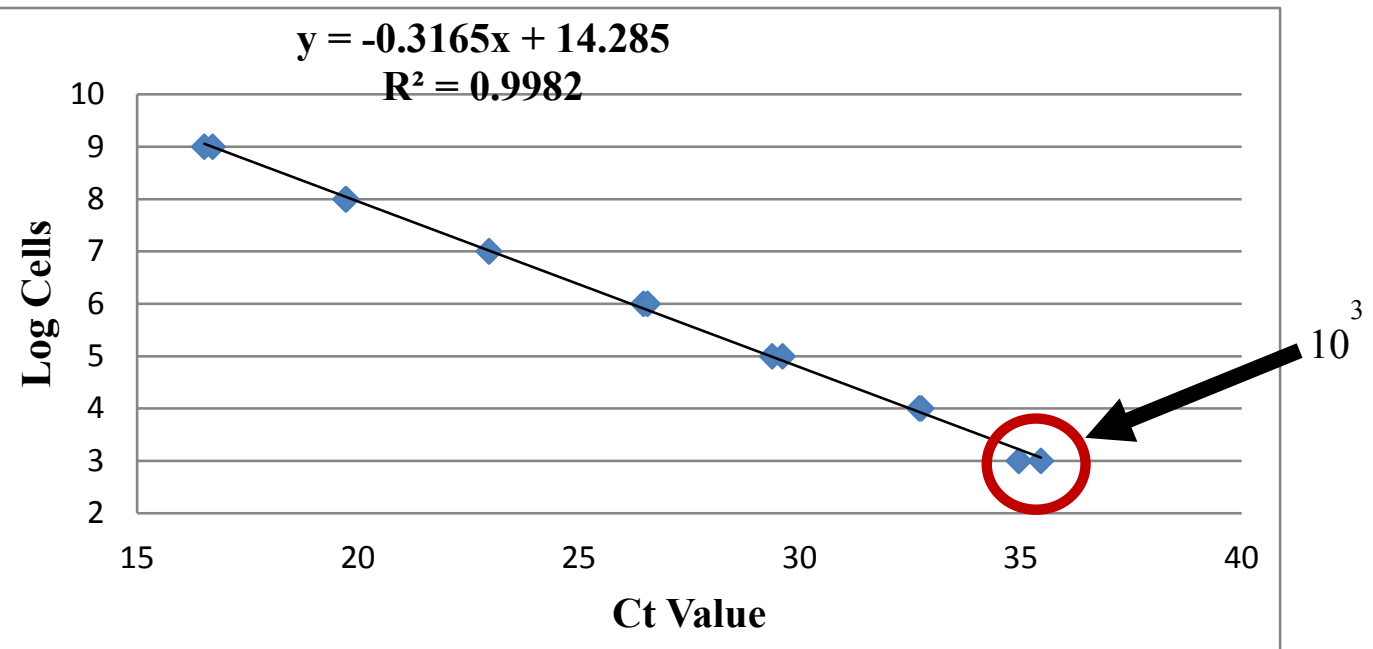

Figure 5: The detection limit $\left(10^{3} \mathrm{CFU} / \mathrm{g}\right)$. Standard curve of species-specific $P$. acidilactici illustrates the detection limit $\left(10^{3} \mathrm{CFU} / \mathrm{g}\right)$. The blue boxes are replicates, red circle indicates variability of $10^{3} \mathrm{CFU} / \mathrm{g}$ replicates, and the black line is the slope.

Table 2: Species-specific primers used for $P$. pentosaceus and $B$. subtilis

\begin{tabular}{c|c|c|c}
\hline \multicolumn{2}{c|}{ Primers } & P. pentosaceus & B. subtilis \\
\hline \multirow{2}{*}{$\begin{array}{c}\text { Species } \\
\text { PCR }\end{array}$} & F & TCACTCTTTACGCCCTTC & CCAACATATAAGACCTCTAC \\
\cline { 2 - 4 } & Size & GCGGGAGCATTACTATTT & TTATTTCATCCCATCCTGAC \\
\hline $\begin{array}{c}\text { Species } \\
\text { qPCR }\end{array}$ & Probe & ACCGCCACGCTAGTTTCA & CCCAACCAGCGATCCATAC \\
\hline
\end{tabular}

Table 3: Species and strain specific primers used for $P$. acidilactici and $L$. plantarum. Species-specific primers for $L$. plantarum are not strain-specific, but amplify a fragment of $233 \mathrm{bp}$ instead of $155 \mathrm{bp}$ with other strains of L. plantarum.

\begin{tabular}{c|c|c|c}
\hline \multicolumn{2}{c|}{ Primers } & P. acidilactici & L. plantarum \\
\hline \multirow{2}{*}{$\begin{array}{c}\text { Species } \\
\text { PCR }\end{array}$} & $\mathrm{F}$ & CGGTTGAGAAGTGAAGTTA & CCCGTAAACGCAAAGATAA \\
\cline { 2 - 4 } & Size & GGTTGAAGCTTATGATGG & TTCAATATGCTCTCCGTC \\
\hline $\begin{array}{c}\text { Species } \\
\text { qPCR }\end{array}$ & Probe & TTTAGGGAAGTCGGTGCGG & CGATGATTAAATCGGTGACAAATTTGGTC \\
\hline \multirow{3}{*}{$\begin{array}{c}\text { Strain } \\
\text { PCR }\end{array}$} & F & TCTCGCCGATTGAATATC & AGCCGCTATGGGTATAAC \\
\cline { 2 - 4 } & Size & TAGGTCCCGCAATTTAAG & AAATCACCGACCACGTAA \\
\hline
\end{tabular}




\subsection{Microbiome 16S rRNA Sequencing}

Genomic DNA was isolated from 102 samples: day 22 guts' lumen contents and mucosa layer of the duodenum, jejunum, ileum, and ceca and day 22 feces from pens 1-6. 16S rRNA gene sequencing was performed (LC Sciences, Houston, TX) by amplifying across the V4 region, using the standard primers 515F and 806R, followed by paired-end sequencing on an Illumina MiSeq (Houston, TX) (Walters et al., 2015).

LC Sciences performed raw data reads processing and OTU clustering. Pairedend reads were merged and clustered based on a sequence identity $>97 \%$, representing an OTU (Operational Taxonomic Unit). The taxonomy annotation for each OTU was derived from the Ribosomal Database Project and NT-16S microbial database based on the NCBI GenBank Nucleotide database.

\subsection{Statistical Analysis}

All gut samples were analyzed using JMP Pro 12.0 (SAS Institute Inc., Cary, NC) and due to the small sample size, only the Fischer's Exact Test was used. Values were considered statistically different across treatment at $\mathrm{P} \leq 0.05$.

The 16S rRNA sequencing data report was imported into PRIMER 6; the square root of relative abundances (percent of total sequence reads/sample) was taken to transform the data and reduce variability. Bray Curtis similarity and ANOSIM were used to analyze differences between probiotic treatment and control sample groups. Sample clustering was visualized using grouped hierarchical clustering. 


\section{RESULTS}

\subsection{Weight Measurements}

On days 1,22 , and 25 , individual weight measurements of both control and treated birds were taken prior to gut sampling. Group pen weight and feed weight were measured weekly, and body weight gain and feed conversion ratio (feed intake/ body weight gain) were calculated. The average and standard deviation was determined for body weight gain, feed intake, and feed conversion ratio (Table 4). There were no significant differences in body weight gain, feed intake, and feed conversion ratio between the treated and control birds (ANOVA P > 0.9).

Table 4: Effects of probiotic supplementation on broiler chicken growth performance. The average and standard deviation of body weight gain, feed intake, and feed conversion ratio (FCR) for days 1-11, 11-22, and 22-25. The birds were fed a starter diet to begin with and then switched to a grower diet on day 11. Days 22-25 represent termination of probiotic administration.

\begin{tabular}{|c|c|c|c|c|c|c|}
\hline \multirow[b]{2}{*}{ Days } & \multicolumn{3}{|c|}{ TREATMENT } & \multicolumn{3}{|c|}{ CONTROL } \\
\hline & $1-11$ & 11-22 & $22-25$ & $1-11$ & $11-22$ & $22-25$ \\
\hline $\begin{array}{l}\text { Weight Gain } \\
(\mathrm{g} / \mathrm{bird} / \mathrm{d})\end{array}$ & $33 \pm 0.7$ & $58 \pm 3.9$ & $64 \pm 2.8$ & $34 \pm 0.6$ & $58 \pm 2.6$ & $63 \pm 4.9$ \\
\hline $\begin{array}{l}\text { Feed Intake } \\
(\mathrm{g} / \mathrm{bird} / \mathrm{d})\end{array}$ & $39 \pm 0.7$ & $89 \pm 5.8$ & $114 \pm 7.6$ & $40 \pm 0.9$ & $89 \pm 17$ & $110 \pm 13$ \\
\hline $\begin{array}{l}\text { FCR } \\
(\mathrm{g} / \mathrm{g})\end{array}$ & $1.2 \pm 0.03$ & $1.5 \pm 0.01$ & $1.8 \pm 0.07$ & $1.2 \pm 0.03$ & $1.5 \pm 0.3$ & $1.8 \pm 0.3$ \\
\hline
\end{tabular}

\subsection{Probiotic Survival in Poultry Unit Water}

During a 24-hour test incubation, the concentration of $B$. subtilis in the poultry unit water remained relatively stable in cell counts over time from the initial time point $1.57 \times 10^{4}$ $\mathrm{CFU} / \mathrm{ml}$ to $1.44 \times 10^{4} \mathrm{CFU} / \mathrm{ml}$ after 6 hours, and then to $1.49 \times 10^{4} \mathrm{CFU} / \mathrm{ml}$ after 24 hours. 
Unfortunately, the lactic acid bacteria in this test were not detectable on MRS plates and even time 0 had less than $250 \mathrm{CFU} / \mathrm{ml}$.

\subsection{Background Probiotic Bacteria in Feeds}

Probiotic bacteria were detected in both chicken feeds (feed-endogenous) using speciesspecific primers (Table 5). P. acidilactici was detected by PCR in both diets while qPCR indicated a slight decrease in concentration from diet 1 to diet 2. L. plantarum concentrations also decreased from diet 1 to diet 2. However, L. plantarum was not detected by PCR in either diet. Similarly, P. pentosaceus was not detected in either diet using PCR, while qPCR detected a very low concentration in diet 1 and nothing in diet 2 . B. subtilis was not detected in either of the two diets regardless of detection method (Table 5).

Table 5: Detection and concentrations of probiotic bacteria in the feed using speciesspecific primers. Presence of probiotic bacteria in the feed as determined by PCR indicated by a + or - sign. Concentrations, near the standard curve detection limit $\left(10^{3}\right.$ $\mathrm{CFU} / \mathrm{g}$ ) are underlined and those below the detection limit are bolded and underlined. ND indicates no detection.

\begin{tabular}{cccccc}
\hline $\begin{array}{c}\text { Feed } \\
\text { Sample }\end{array}$ & Method & P. acidilactici & P. pentosaceus & L. plantarum & B. subtilis \\
\hline $\begin{array}{c}\text { Diet \#1 } \\
\text { (Starter) }\end{array}$ & PCR & + & - & - & - \\
\hline qPCR & $\underline{8.5 \times 10^{3}}$ & $\underline{\mathbf{9 . 9 \times 1 0 ^ { 2 }}}$ & $\underline{2.1 \times 10^{3}}$ & ND \\
$\begin{array}{c}\text { Diet \#2 } \\
(\text { Grower) }\end{array}$ & PCR & + & - & - & - \\
\hline
\end{tabular}




\subsection{Probiotic Bacteria in Fecal Samples}

In an initial study using species-specific primers, probiotic bacterial cells were quantified by qPCR in feces from days 3,7 , and 12 (Table 6). The average DNA concentration for these fecal samples, was $29 \pm 14 \mathrm{ng} / \mu \mathrm{l}$. $P$. acidilactici, $P$. pentosaceus, and $L$. plantarum species were present in all samples and decreased in concentration from day 3 to day 7 . B. subtilis was rarely detected and many cell concentrations were below the $\mathrm{qPCR}$ detection limit, as defined by standard curves (Figure 6). Since the qPCR results were often at or below detection limits (Table $4 \& 5$ ) presence/absence PCR was used to detect probiotic bacteria in the rest of the study.

Table 6: Concentration of probiotic bacteria in fecal samples using species-specific primers. TRT: treatment pens 1-3; CON: control pens 4-6. The three qPCR values correspond to the treatment or control pens, with the top value representing the first pen number (pen 1 or pen 4 ), the second (pen 2 or pen 5), and the third (pen 3 or pen 6). Concentrations, at the standard curve detection limit $\left(10^{3} \mathrm{CFU} / \mathrm{g}\right)$ are underlined and those below the detection limit are bolded and underlined. ND indicates no detection.

\begin{tabular}{|c|c|c|c|c|c|c|c|c|}
\hline \multirow{2}{*}{$\begin{array}{c}\text { Fecal } \\
\text { Sample }\end{array}$} & \multicolumn{2}{|c|}{ P. acidilactici } & \multicolumn{2}{|c|}{ P. pentosaceus } & \multicolumn{2}{|c|}{ L. plantarum } & \multicolumn{2}{|c|}{ B. subtilis } \\
\hline & TRT & $\mathrm{CON}$ & TRT & $\mathrm{CON}$ & TRT & CON & TRT & CON \\
\hline \multirow{3}{*}{ Day 3} & $1.2 \times 10^{9}$ & $1.4 \times 10^{8}$ & $2.9 \times 10^{5}$ & $7.0 \times 10^{6}$ & $2.0 \times 10^{8}$ & $1.3 \times 10^{7}$ & ND & ND \\
\hline & $8.3 \times 10^{8}$ & $1.3 \times 10^{9}$ & $6.4 \times 10^{4}$ & $4.4 \times 10^{5}$ & $4.6 \times 10^{7}$ & $1.5 \times 10^{8}$ & $2.6 \times 10^{3}$ & ND \\
\hline & $8.1 \times 10^{8}$ & $7.1 \times 10^{8}$ & $9.1 \times 10^{3}$ & $8.3 \times 10^{4}$ & $4.9 \times 10^{7}$ & $8.5 \times 10^{7}$ & $\underline{4.8 \times 10^{2}}$ & ND \\
\hline \multirow{3}{*}{ Day 7} & $1.6 \times 10^{5}$ & $7.4 \times 10^{3}$ & $\underline{4.5 \times 10^{3}}$ & $\underline{9.8 \times 10^{3}}$ & $1.1 \times 10^{5}$ & $1.2 \times 10^{4}$ & ND & ND \\
\hline & $1.4 \times 10^{5}$ & $3.6 \times 10^{5}$ & $\underline{3.9 \times 10^{3}}$ & ND & $1.0 \times 10^{5}$ & $1.4 \times 10^{5}$ & ND & ND \\
\hline & $9.3 \times 10^{4}$ & $4.4 \times 10^{4}$ & ND & ND & $2.5 \times 10^{4}$ & $2.3 \times 10^{4}$ & ND & ND \\
\hline \multirow{3}{*}{ Day 12} & $2.0 \times 10^{5}$ & $8.9 \times 10^{4}$ & $3.7 \times 10^{3}$ & $\underline{1.7 \times 10^{3}}$ & $7.9 \times 10^{4}$ & $2.0 \times 10^{4}$ & $\underline{6.7 \times 10^{2}}$ & ND \\
\hline & $4.0 \times 10^{4}$ & $1.1 \times 10^{5}$ & $\underline{3.2 \times 10^{3}}$ & $\underline{3.7 \times 10^{2}}$ & $4.8 \times 10^{4}$ & $4.8 \times 10^{6}$ & ND & ND \\
\hline & $1.2 \times 10^{6}$ & $5.4 \times 10^{4}$ & $\underline{8.4 \times 10^{2}}$ & $2.6 \times 10^{3}$ & $6.5 \times 10^{5}$ & $2.1 \times 10^{4}$ & ND & ND \\
\hline
\end{tabular}


In a more detailed effort, standard PCR with both strain and species-specific primers was used to detect probiotic presence/absence in a broad range of fecal samples collected from each pen throughout the trial (Figure 6). Species-specific primers consistently detected $P$. acidilactici and L. plantarum in mostly all control and treated pens within one hour of probiotic administration, throughout the experiment, and after probiotic administration was halted (data not shown). Because of this consistent interference from feed-endogenous bacteria, no information could be discerned about the administered probiotic strains. P. pentosaceus species-specific primers also detected these bacteria in most treated and control pens throughout the trial. Although P. pentosaceus was often detected in control pens it was more often seen in feces from probiotic-fed pens (Figure 6C). B. subtilis however, was detected in feces within one hour of probiotic administration, and was, with two exceptions, only detected in treated birds. B. subtilis was not detected after probiotic administration ended (Figure 6D).

To overcome interference from feed-endogenous bacteria, strain specific primers for $P$. acidilactici and $L$. plantarum were used to detect the administered probiotic strains. These primers detected both $P$. acidilactici and L. plantarum only in treated pens within two hours of probiotic administration and again ten days later. P. acidilactici was detected in a few probiotic-fed pens across the remainder of the probiotic trial, while $L$. plantarum was detected in at least one probiotic-fed pen on all remaining days except day 16. Both bacteria were no longer detected once probiotic administration was halted (Figure 6A \& 6B). Design of strain specific primers for P. pentosaceus was unsuccessful (J. VanderKelen, personal communication, January 2018). 
A.

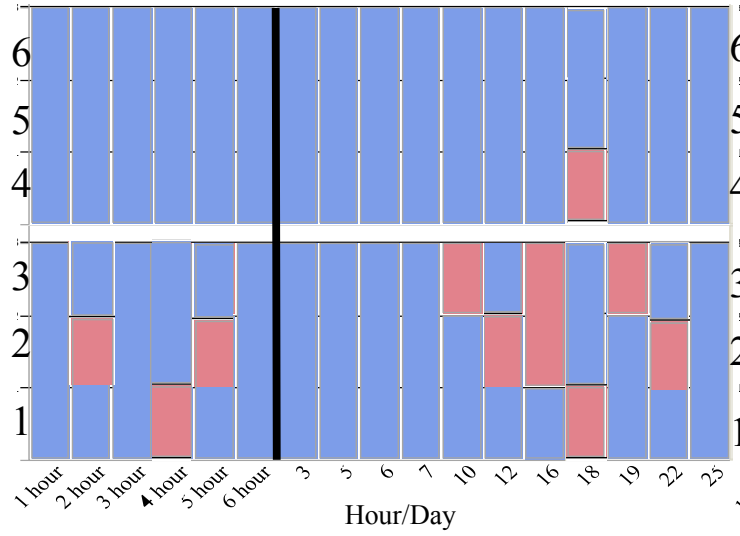

C.
B.

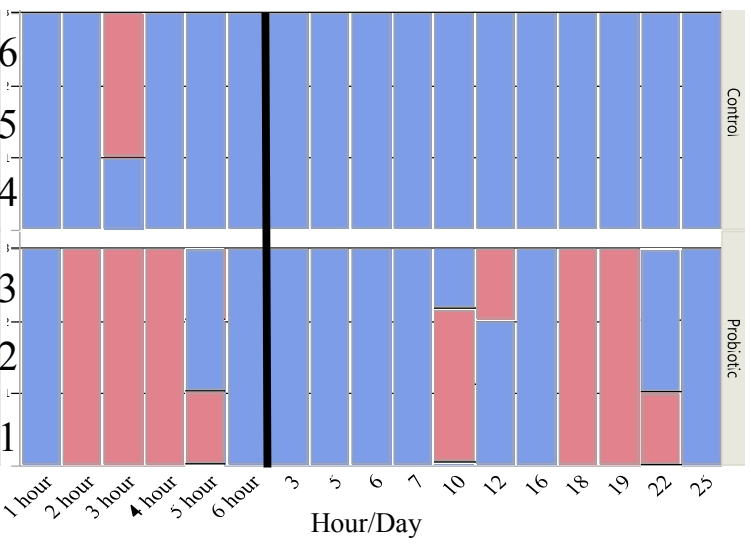

D.

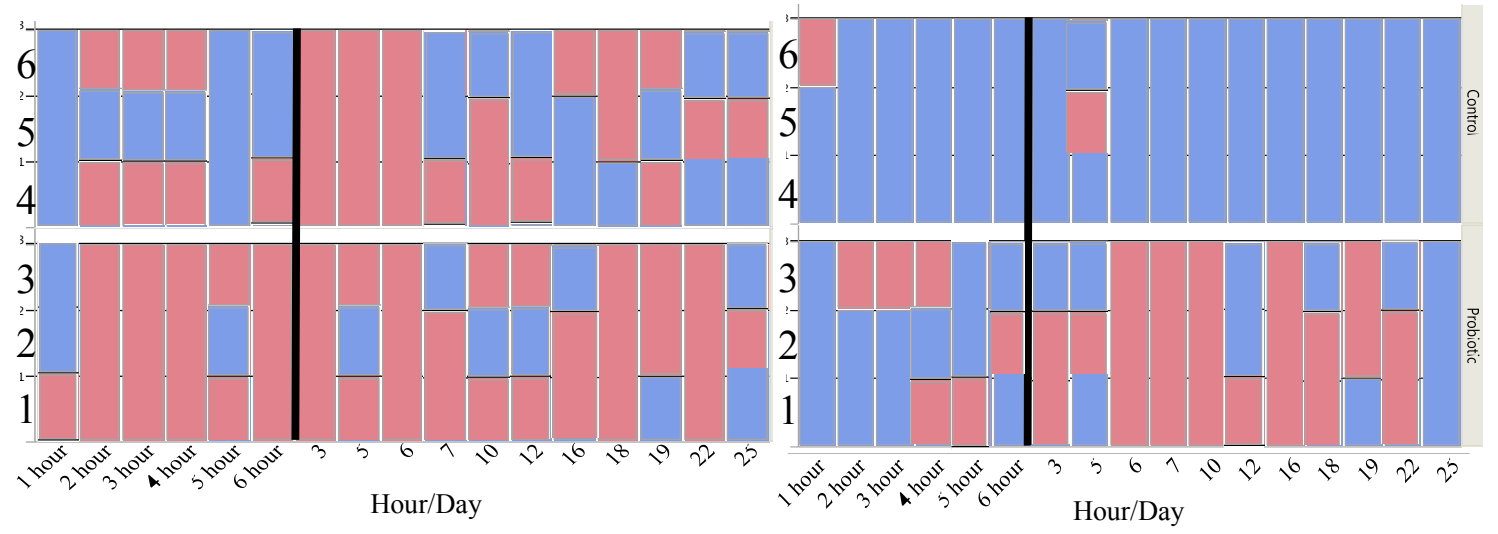

Figure 6: PCR detection of probiotic bacteria in the feces using strain and speciesspecific primers. (A) detection of $P$. acidilactici using strain specific primers (B) detection of $L$. plantarum using strain specific primers (C) detection of $P$. pentosaceus using speciesspecific primers (D) detection of $B$. subtilis using species-specific primers. Probiotic bacterial strain presence (red) or absence (blue). Fecal samples were collected hourly for a total of six hours on the first day and daily thereafter (separated by black line). The top panel of each graph represents the control pens (4-6), the bottom panel the treatment pens (1-3). For each time point, one of three boxes correlate to a specific pen number corresponding to treatment (1-3) or control (4-6) pens. Time point Day 25 probiotic was removed.

\subsection{Detection of Probiotic Species Bacteria in Day 1 Gut Samples}

E. coli was used as a positive control to ensure that bacterial DNA was detectable in all day 1 gut samples. E. coli was detected in day 1 gut samples from all control and treatment birds (data not shown). B. subtilis and P. pentosaceus were not detected by species-specific PCR primers in almost all day 1 gut samples (Table 7). However, 
species-specific primers detected L. plantarum and P. acidilactici in all four gut compartments (in both treated and control birds) with P. acidilactici detected more frequently than L. plantarum. Strain specific PCR primers for $L$. plantarum and $P$. acidilactici did not detect the administered strains in any samples (data not shown).

Table 7: Detection of probiotic bacteria in day 1 gut samples according to bird and pen using species-specific primers. Treatment boxes: increments of 2 boxes correspond to pens 1,2, and 3. Control boxes: increments of 2 boxes correspond to pens 4, 5, and 6 . The first box of each corresponding pen is bird 1 and the second box to each pen is bird

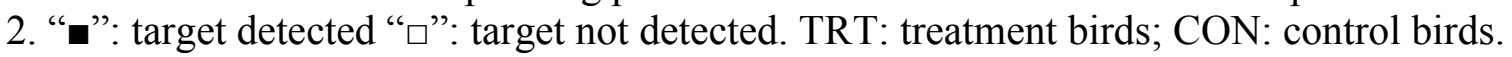

\begin{tabular}{|c|c|c|c|c|c|c|c|c|}
\hline & \multicolumn{2}{|c|}{ P. acidilactici } & \multicolumn{2}{|c|}{ P. pentosaceus } & \multicolumn{2}{|c|}{ L. plantarum } & \multicolumn{2}{|c|}{ B. subtilis } \\
\hline Sample & TRT & CON & TRT & $\mathrm{CON}$ & TRT & CON & TRT & $\mathrm{CON}$ \\
\hline Duodenum & | & 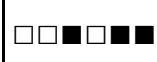 & 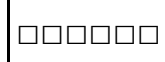 & 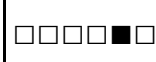 & | & 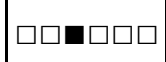 & 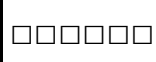 & 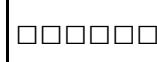 \\
\hline Jejunum & 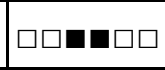 & 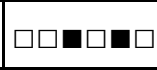 & 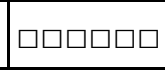 & 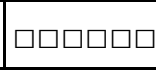 & 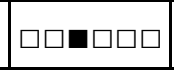 & 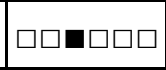 & 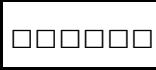 & 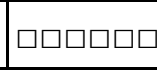 \\
\hline Ileum & 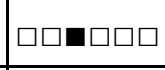 & 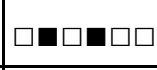 & 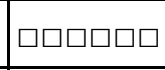 & 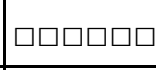 & 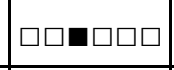 & \begin{tabular}{|l|l|}
$\square(\operatorname{mog}$ \\
\end{tabular} & 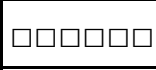 & 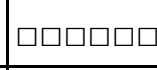 \\
\hline Ceca & 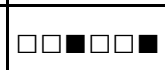 & पवालव & 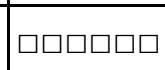 & कपषणमा & कपषमपर & पammo & 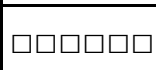 & 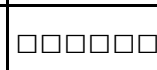 \\
\hline
\end{tabular}

Table 8: Detection of $\boldsymbol{E}$. coli in gut samples. E. coli was used as a positive control to ensure that bacterial DNA was detectable in day 22 and 25 gut samples. The number of birds (max 6) with a positive PCR result for E. coli in each gut compartment is shown. C: control birds; T: treatment birds. L: lumen samples; M: mucosa samples.

\begin{tabular}{rr|cccccccc}
\hline & \multicolumn{2}{|c}{ Duodenum } & \multicolumn{2}{c}{ Jejunum } & \multicolumn{2}{c}{ Ileum } & \multicolumn{2}{c}{ Ceca } \\
\hline \multicolumn{2}{c}{ Sample } & L & M & L & M & L & M & L & M \\
\hline \multirow{2}{*}{ Day 22 } & C & 2 & 6 & 4 & 6 & 6 & 6 & 6 & 6 \\
& $\mathrm{~T}$ & 5 & 6 & 5 & 6 & 6 & 6 & 6 & 6 \\
\hline \multirow{2}{*}{ Day 25 } & $\mathrm{C}$ & 5 & 6 & 6 & 6 & 6 & 6 & 6 & 6 \\
& $\mathrm{~T}$ & 5 & 6 & 6 & 6 & 6 & 6 & 6 & 6 \\
\hline
\end{tabular}

\subsection{Probiotic Bacteria in Day 22 Guts Samples}

The average and standard deviation lumen and mucosa DNA concentrations (ng/ $\mu \mathrm{l})$ were calculated for all day 22 gut compartments to ensure that bacterial DNA was present and 
amplifiable (Table 9). E. coli was used as a positive control to ensure bacterial DNA was detectable in day 22 gut samples, however, E. coli was not detected in all gut compartments (Table 8). Species-specific PCR primers detected P. pentosaceus in the jejunal, ileal, and cecal lumen of most treated birds (Table 10). Positive results were seen more often in treated birds compared to the control birds in the ileal lumen and the cecal lumen ( $\mathrm{p}=0.015$, Fisher's Exact Test). Species-specific PCR primers also detected $P$. acidilactici and L. plantarum in most of jejunal, ileal, and cecal lumen samples. These bacteria were also common in the cecal mucosa, indicating probable gut colonization. Strain specific primers detected these two administered strains predominantly in the lumen and rarely in the mucosa samples. P. acidilactici was the least common strain, only rarely detected in the ileal and cecal lumen. L. plantarum was predominantly detected near the end of the gut in the ileal and cecal lumen. Of the four administered probiotic strains, both $L$. plantarum and $B$. subtilis were seen only in the treated birds. $B$. subtilis detection was more common in the jejunal and ileal lumen of treated birds.

The only bird to show the presence of all four administered probiotic strains was bird 2 from pen 2 (Table 10). In this bird, P. acidilactici was detected in both the ileal and cecal lumen. P. pentosaceus and L. plantarum were detected in the jejunal, ileal, and cecal lumen. L. plantarum was also found in the cecal mucosa. B. subtilis was detected in this bird in the jejunal and ileal lumen, as well as the ileal mucosa. This bird was also the only broiler chicken in the experiment with two administered probiotic strains detected in mucosal samples. Many administered probiotic strains were also detected in bird 1 from pen 2. P. acidilactici was detected only in the cecal lumen in bird 1.P. pentosaceus was detected in the jejunal, ileal, and cecal lumen. L. plantarum was detected in the lumen of 
both the ileum and ceca. Unlike bird 2, bird 1 had no detectable $B$. subtilis and there were no probiotic bacteria detected in the mucosal layer of any gut compartment. The two birds from pen 1 had no detectable $P$. acidilactici, rarely detected L. plantarum and $B$. subtilis, and more often detected P. pentosaceus. While no P. acidilactici was detected in bird 1 of pen $3, P$. pentosaceus was detected in the duodenal mucosa, and the jejunal, ileal, and cecal lumen. L. plantarum was detected in this bird only in the ceca lumen, and B. subtilis was found in the jejunal and ileal lumen.

Table 9: Day 22 gut samples genomic DNA concentration (ng/ $\boldsymbol{\mu l})$. Averages \pm standard deviation.

\begin{tabular}{ccccc}
\hline Compartment & Duodenum & Jejunum & Ileum & Ceca \\
\hline Lumen & $6.4 \pm 6.2$ & $2.6 \pm 2.1$ & $2.8 \pm 2.6$ & $139 \pm 65$ \\
Mucosa & $75 \pm 36$ & $13 \pm 20$ & $103 \pm 65$ & $42 \pm 23$ \\
\hline
\end{tabular}


Table 10: Detecting probiotic bacteria in day 22 gut samples according to bird and pen using both strain and species-specific primers. Treatment boxes: increments of 2 boxes correspond to pens 1, 2, and 3. Control boxes: increments of 2 boxes correspond to pens 4, 5, and 6. The first box of each corresponding pen is bird 1 and the second box is bird 2. "ø": target detected " $\square$ ": target not detected. The dash marks indicate no data due to no strain specific primers (P. pentosaceus and B. subtilis). $\downarrow$ : Bird 2 Pen 2 as referred in text.

\begin{tabular}{|c|c|c|c|c|c|c|c|c|}
\hline & \multicolumn{2}{|c|}{ P. acidilactici } & \multicolumn{2}{|c|}{ P. pentosaceus } & \multicolumn{2}{|c|}{ L. plantarum } & \multicolumn{2}{|c|}{ B. subtilis } \\
\hline Sample & Treatment & Control & Treatment & Control & Treatment & Control & Treatment & Control \\
\hline \multicolumn{9}{|c|}{ Strain Specific Primers } \\
\hline Duodenum Lumen & 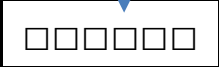 & प्षणम० & - & - & ㅁㅁㅁㅁ & प्मप०म & - & - \\
\hline Duodenum Mucosa & पमिपम & प्म००म & - & - & 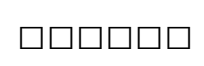 & प्वपम० & - & - \\
\hline Jejunum Lumen & प्म००० & 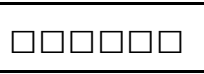 & - & - & $\square \square \square \mathbf{D \square}$ & प्मप०म & - & - \\
\hline Jejunum Mucosa & 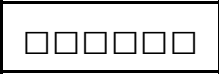 & प्म००० & - & - & पमिम०० & प्मप०म & - & - \\
\hline Ileum Lumen & 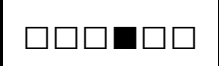 & प्म००० & - & - & $\square \mathbf{m} \square \square$ & प्म००० & - & - \\
\hline Ileum Mucosa & 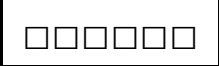 & प्मप०० & - & - & 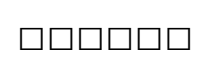 & प्मप०० & - & - \\
\hline Ceca Lumen & $\square \square \mathbf{m} \square \square$ & 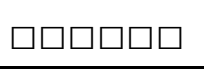 & - & - & 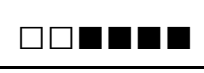 & प्मप०म & - & - \\
\hline Ceca Mucosa & 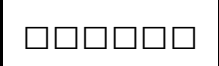 & प्मपम् & - & - & $\square \square \square \mathbf{D \square}$ & 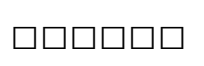 & - & - \\
\hline \multicolumn{9}{|c|}{ Species-Specific Primers } \\
\hline Duodenum Lumen & $\square \mathbf{m} \square \square \square$ & 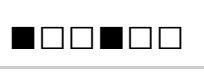 & $\mathbf{m}+\square \square \square$ & 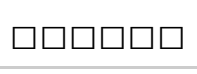 & $\square \square \square \square \square \square$ & 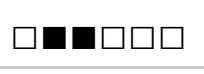 & - $\square \square \square \square \square$ & 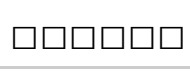 \\
\hline Duodenum Mucosa & 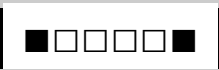 & 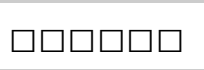 & 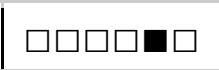 & पमिम०० & 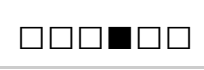 & 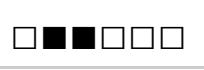 & 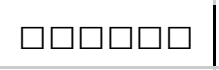 & 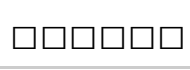 \\
\hline Jejunum Lumen & ص日um & घene & 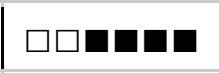 & 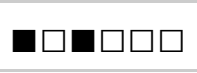 & 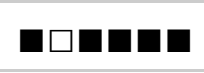 & घumen & 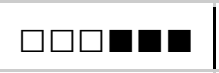 & 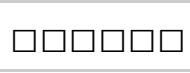 \\
\hline Jejunum Mucosa & घमिम०० & 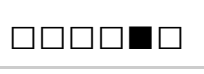 & 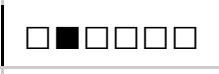 & म००णम० & 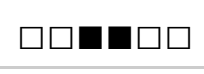 & पिमप०म & पिमप०म & $\square \square \square \square \square \square$ \\
\hline Ileum Lumen & n日man & ص日um & घuman & $\mathbf{0} \square \square \square \square$ & G日um & घnघm & प्मचघ & 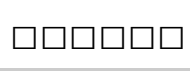 \\
\hline Ileum Mucosa & 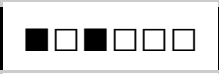 & $\square \square \square \square \square$ & 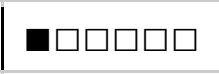 & 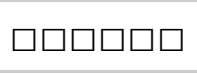 & $\square \square \mathbf{D \square \square}$ & म०णम०० & म००णम० & 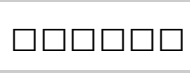 \\
\hline Ceca Lumen & n日man & घqun & 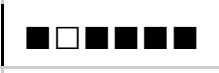 & पमिम०० & mann & 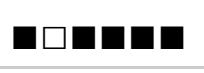 & 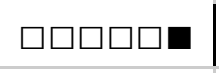 & 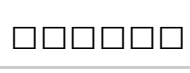 \\
\hline Ceca Mucosa & $\mathbf{D} \square \mathbf{m}$ & $\mathbf{E} \square \mathbf{m} \square$ & $\square \square \square \square \square \square$ & प्विम० & anam & שnسm & 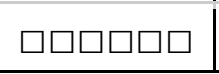 & प्विम \\
\hline
\end{tabular}




\subsection{Detection of Probiotic Bacteria in Day 25 Guts}

E. coli was used as a positive control to ensure bacterial DNA from day 25 gut samples was present and amplifiable. Similar to day 22, E. coli was not detected in a couple day 25 duodenal lumen gut samples (Table 8 ). On day 25 , three days after probiotic administration was halted, both $P$. pentosaceus and $B$. subtilis were observed more often in the control birds, while L. plantarum was occasionally detected in several birds (Table 11). All probiotic strains were also detected in a few mucosa samples as well. There were no significant differences by treatment for all categories of day 25 gut samples.

Table 11: Detection of probiotic bacteria in day 25 gut samples according to bird and pen using both strain and species-specific primers. Treatment boxes: increments of 2 boxes correspond to pens 1,2, and 3. Control boxes: increments of 2 boxes correspond to pens 4, 5, and 6 . The first box of each corresponding pen is bird 1 and the second box is bird 2. "ø": target detected "口": target not detected. Strain specific PCR primers, marked by a star, detected administered $P$. acidilactici \& $L$. plantarum strains, and species-specific primers were used to detect $P$. pentosaceus $\& B$. subtilis. TRT: treatment birds; CON: control birds. L: lumen samples; M: mucosa samples.

\begin{tabular}{|c|c|c|c|c|c|c|c|c|c|}
\hline \multirow{2}{*}{\multicolumn{2}{|c|}{ Sample }} & \multicolumn{2}{|c|}{ *P. acidilactici } & \multicolumn{2}{|c|}{ P. pentosaceus } & \multicolumn{2}{|c|}{ *L. plantarum } & \multicolumn{2}{|c|}{ B. subtilis } \\
\hline & & TRT & $\mathrm{CON}$ & TRT & $\mathrm{CON}$ & TRT & $\mathrm{CON}$ & TRT & CON \\
\hline \multirow[b]{2}{*}{ Duodenum } & $\mathrm{L}$ & & & & & & & प्मपर्ष & 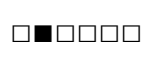 \\
\hline & $\mathrm{M}$ & 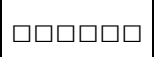 & 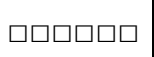 & 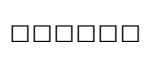 & 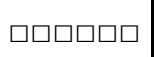 & 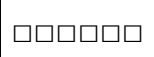 & 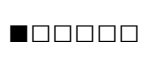 & 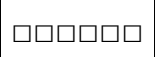 & 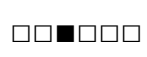 \\
\hline \multirow[b]{2}{*}{ Jejunum } & $\mathrm{L}$ & 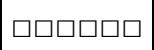 & पमपषमप & & & 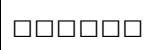 & 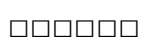 & 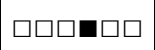 & תחתחת \\
\hline & $\mathrm{M}$ & पवप्रमप & प्पषम० & 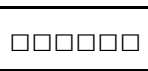 & प्वप्र & प्मपरम & 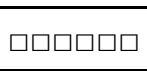 & 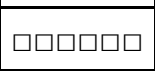 & 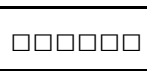 \\
\hline \multirow[b]{2}{*}{ Ileum } & $\mathrm{L}$ & पमिपम & प्मप०० & 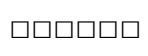 & & पमपम०० & & 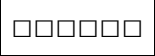 & प्मप०त \\
\hline & $\mathrm{M}$ & पमपणम० & प्मप०० & पमपम०ण & पम०णम० & 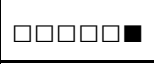 & प्मपम० & पम००ण & - \\
\hline \multirow[b]{2}{*}{ Ceca } & $\mathrm{L}$ & पमप०म० & प्मप०० & पमप०ण & $\square[\square \square \square \boldsymbol{~}$ & 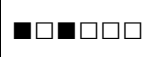 & प्मपम० & पमपणम & पमप०मप \\
\hline & $\mathrm{M}$ & 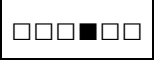 & 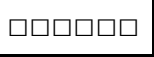 & वप्रम० & 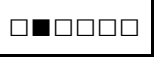 & 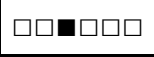 & प्वपम० & 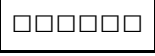 & 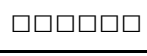 \\
\hline
\end{tabular}




\subsection{Microbiome Data}

Out of 102 genomic DNA samples from day 22 (guts lumen and mucosa samples from 12 birds plus feces from pens 1-6) sent to LC Sciences for 16S rRNA gene (microbiome) sequencing, only 59 produced high quality data good enough for further analysis (Table 12). Comparison of microbiomes at the family taxonomy level did not show a significant difference between treatments: in the feces, or any gut compartment, or when all compartments were aggregated (data not shown). Despite a lack of treatment effect, interesting differences in the microbiomes from lumen and mucosa samples were easily visible in the jejunum $(p=0.07$ ANOSIM), noticeable in the ileum $(p=0.67$ ANOSIM), but disappeared in the ceca (Figure 7, 8, 9).

Table 12: Number of gut samples producing usable 16S sequence data from day 22 . All fecal samples (pens 1-6) from day 22 produced usable data.

\begin{tabular}{ccccc}
\hline Compartment & Duodenum & Jejunum & Ileum & Ceca \\
\hline Lumen & 3 & 8 & 7 & 12 \\
Mucosa & 2 & 5 & 4 & 12 \\
\hline
\end{tabular}




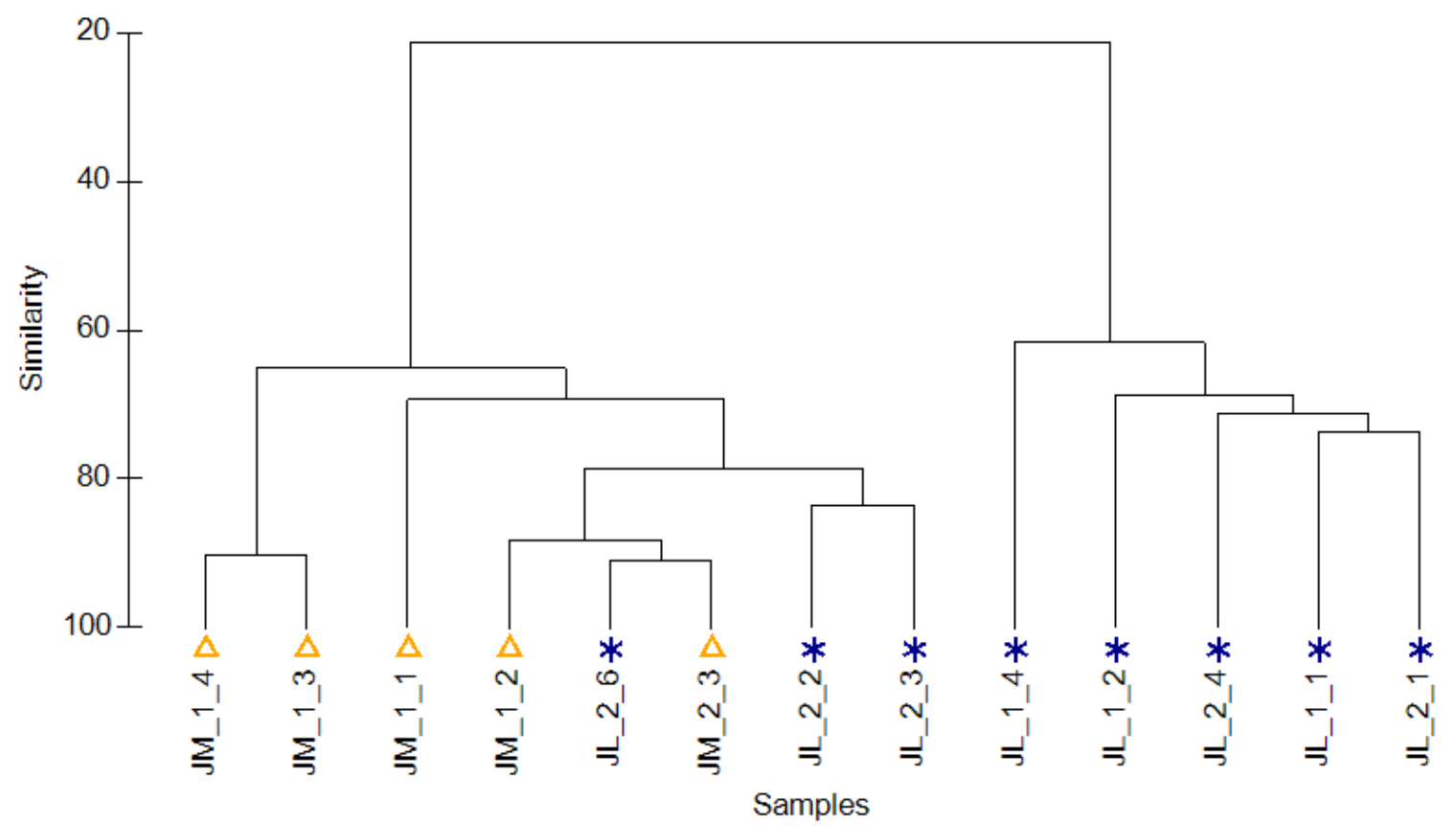

Figure 7: Cluster analysis of jejunal lumen and mucosa microbiome data at the family taxonomy level. JL: jejunal lumen; JM: jejunal mucosa, the central number corresponds to bird 1 or 2 , and the last digit is the pen number. The asterisk represents lumen while the triangle is the mucosa.

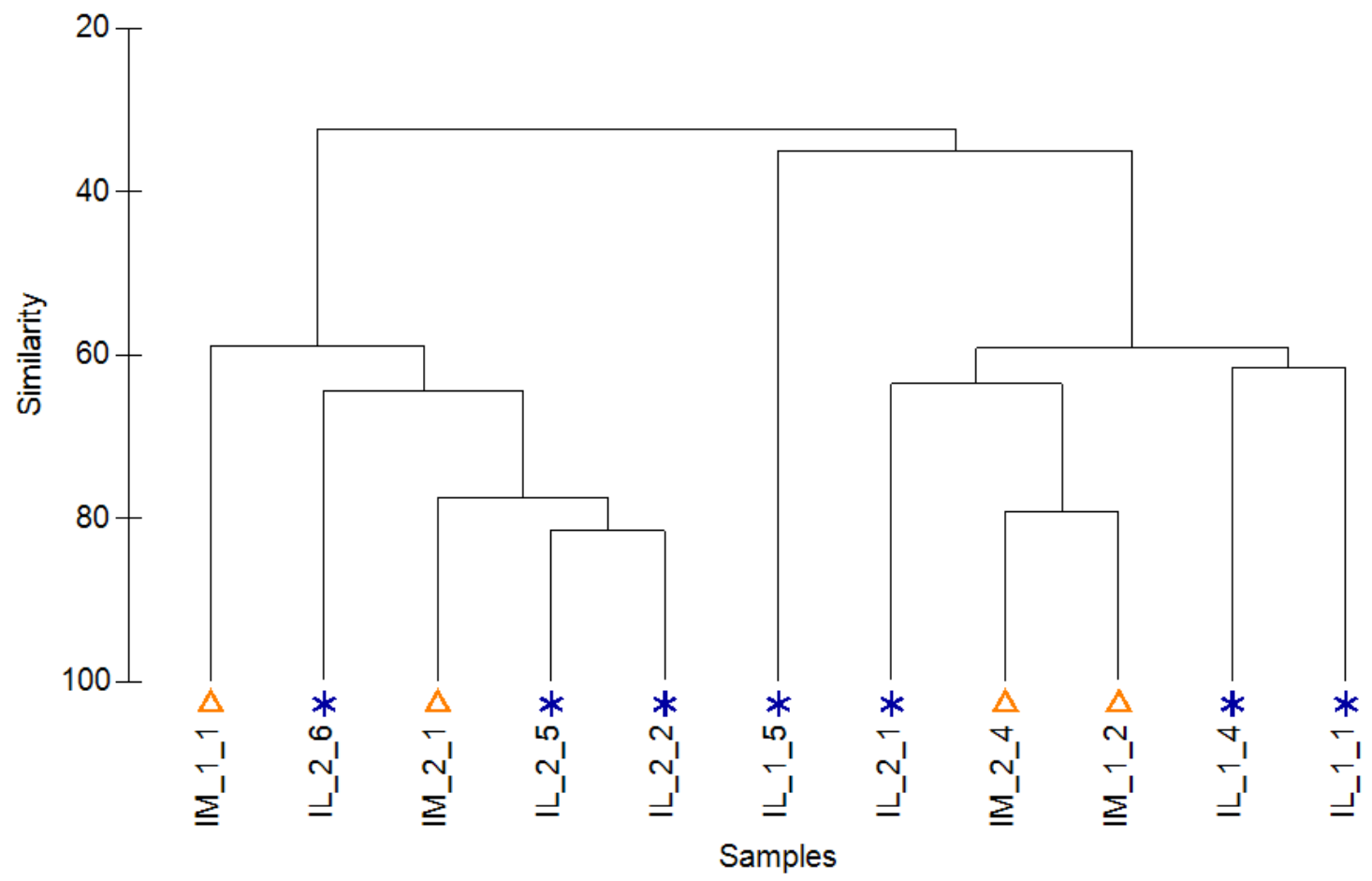

Figure 8: Cluster analysis of ileal lumen and mucosa microbiome data at the family taxonomic level. IL: ileal lumen; IM: ileal mucosa, the central number corresponds to bird 1 or 2, and the last digit is the pen number. The asterisk represents lumen while the triangle is the mucosa. 


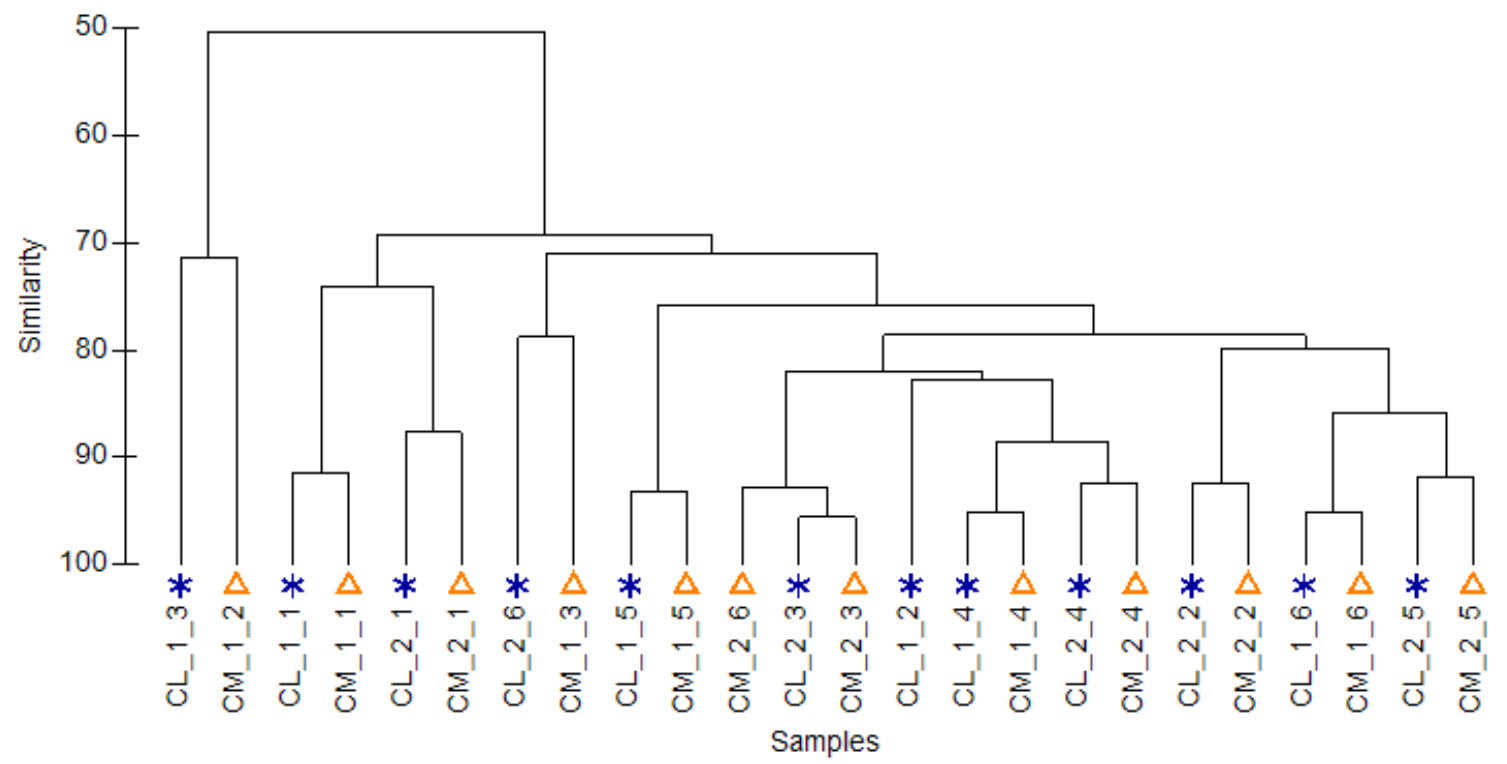

Figure 9: Cluster analysis of cecal lumen and mucosa microbiome data at the family taxonomic level. CL: cecal lumen; CM: cecal mucosa, the central number corresponds to bird 1 or 2, and the last digit is the pen number. The asterisk represents lumen while the triangle is the mucosa.

Alpha diversity in day 22 gut samples was calculated as average sequence reads and species counts per sample (Table 13). The ceca (both lumen and mucosa) had the highest average number of species identified (Table 13) while feces had the lowest 145 \pm 32 . Feces also had the lowest average number of sequence reads at $15795 \pm 2906$. There were no significant differences in alpha diversity by treatment (data not shown).

Table 13: Microbiome alpha diversity. The average and standard deviation of sequence reads and observed species in day 22 gut samples.

\begin{tabular}{c|c|cccc}
\hline & & Duodenum & Jejunum & Ileum & Ceca \\
\hline \multirow{4}{*}{ Reads } & Lumen & 29,290 & 27,075 & 31,114 & $25,422 \pm 9,250$ \\
& & $\pm 14,143$ & $\pm 15,642$ & $\pm 15,884$ & 28,994 \\
& Mucosa & $22,473 \pm 13$ & 33,209 & $22,248 \pm 8,830$ & $\pm 14,101$ \\
\hline \multirow{3}{*}{ Species } & Lumen & $295 \pm 44$ & $212 \pm 117$ & $217 \pm 111$ & $327 \pm 118$ \\
& Mucosa & $317 \pm 12$ & $243 \pm 40$ & $214 \pm 109$ & $327 \pm 115$ \\
\hline
\end{tabular}




\section{DISCUSSION}

\subsection{Testing the Probiotic Formula}

The goal of this study was to identify probiotic gut localization and colonization in broiler chickens after 22 days of probiotic administration. The probiotic treatment bacteria were hypothesized to survive the chicken gastrointestinal tract and colonize the cecal gut compartment. The probiotic bacteria were expected to transit the gastrointestinal tract as intact cells and exit in the feces within a couple hours immediately following administration. Overall, the birds fed probiotics were predicted to have an improved growth performance with an increase in weight gain. Probiotic treatment bacteria were detected in the guts and fecal samples using probiotic strain and species-specific primers (Figure 6; Tables 6, 7, 10, 11). However, the probiotic detection methods used in this study had limitations including a detection limit of $10^{3} \mathrm{CFU} / \mathrm{g}$, and interference from feed-associated bacteria.

\subsection{Low Concentrations of Probiotic Species Near Detection Limit}

Low concentrations of probiotic bacterial species were identified in several fecal samples at or below the detection limit $\left(10^{3} \mathrm{CFU} / \mathrm{g}\right)$ causing probiotic presence detection problems. DNA target bands could sometimes be seen with PCR, indicating a positive detection result even when qPCR failed (Table 5 \& Figure 6). Alternatively, in other cases qPCR could detect low cell counts of probiotic bacteria while PCR produced some negative results (Table $5 \& 6$; Figure 6). At $10^{3} \mathrm{CFU} / \mathrm{g}$ starting material and assuming $100 \%$ bacterial cell lysis and DNA capture, $4 \mu \mathrm{l}$ of DNA should contain 40 target templates. However, the lab procedures used in this study result in about $10-20 \%$ 
bacterial cell lysis and DNA capture (J. VanderKelen, personal communication, May 2017). Thus, template presence in the final $4 \mu \mathrm{l}$ of DNA would likely be random when target cells are below $10^{3} \mathrm{CFU} / \mathrm{g}$ in the sample, making these variable PCR results not too surprising. The qPCR results in Table 5 indicate probiotic species at or below the detection limit $\left(10^{3} \mathrm{CFU} / \mathrm{g}\right)$, thus administered probiotic strain concentrations would likely be even lower. Therefore, qPCR was discontinued as it was considered too expensive for a presence/absence assay. Light bands of probiotic strains were detected in most gut samples and sometimes observed in the fecal PCR data, indicating low levels of treatment probiotic in the samples, however, multiple PCR assays (2-3) were performed throughout the study to confirm negative results.

E. coli was used as a positive control to ensure that bacterial DNA was present and amplifiable in days 1, 22, and 25 gut samples. E. coli, a dominant species in the early life of chickens (Awad et al., 2016) was detected in all day 1 gut samples (Table 8). However, E. coli was not detected in a few duodenal and jejunal lumen gut samples from both days 22 and 25 (Table 8 ). E. coli decreases in the upper GI tract during a chicken's second week of life and remains in the lower chicken intestines at low abundances throughout the animal's life (Awad et al., 2016; Oakley et al., 2014). The presence of E. coli, a known chicken gut colonizer, overall helped understand the treatment probiotic gut results and served as a useful positive control.

\subsection{Probiotic Bacterial Survival in Poultry Unit Water}

The probiotic company and Blajman et al. (2014) suggest the water delivery method of probiotic treatment would be more effective than through feed. The Bacillus probiotic 
held in poultry unit water maintained a steady concentration $\left(\sim 1.50 \times 10^{4} \mathrm{CFU} / \mathrm{ml}\right)$ over a 24-hour incubation period, demonstrating a minimal effect of the water carrier. However, the lactic acid probiotics were not culturable in this plating experiment, which is consistent with previous observations of decreased culturability for lactic acid bacteria in some conditions where the cells may enter a Viable But Not Culturable (VBNC) state (J. VanderKelen, personal communication, May 2018). Although the plating experiment demonstrated possible probiotic die off, all treatment probiotic bacteria were detected in some gut and fecal samples, indicating treatment probiotics did survive in some birds (Table 10 and Figure 6). This study acknowledges there was no evidence to determine live administered bacteria transiting the gut. However, high cell counts in feces indicates bacterial growth instead of detecting only DNA throughout the GI tract. Also, the administered bacteria were rarely detected in the upper intestinal tract compared to the lower, implying the presence of intact bacterial cells as well.

Interestingly, the probiotic die off mentioned above further explains fecal results. Transit time detection samples were taken the first 6 hours immediately following probiotic administration and the probiotic bacteria were detected in most of these hourly fecal samples (Figure 6). However, when the early daily samples (days 3-9) were assayed, administered strains of $P$. acidilactici and L. plantarum were not detected, whereas $B$. subtilis was detected throughout probiotic administration (Figure 6). These negative results for $P$. acidilactici and $L$. plantarum were most likely due to low concentrations of probiotics in the water after 24 hours, as indicated by the decrease in cell counts from the plating experiment. As the chickens grew larger and thirstier by day 10 , the probiotic water was refreshed twice daily, increasing the amount of inoculum by 
reducing the time for cell die off. As a result, administered strains of $P$. acidilactici and $L$. plantarum were detected in the fecal samples once again (Figure 6A \& 6B).

\subsection{Species-Specific Primers Cannot Distinguish Probiotic Strains}

The species-specific PCR primers for P. acidilactici, L. plantarum, and P. pentosaceus used in these assays detected feed-endogenous probiotic bacteria, thus interfering with administered probiotic strain detection (Figure 6C; P. acidilactici and L. plantarum data not shown). The species-specific primers of $P$. acidilactici, L. plantarum, and $P$. pentosaceus could not distinguish between these two sources, thus strain specific primers were used (Table 3). However, strain specific detection of $P$. pentosaceus in this study was not possible due to a lack of strain specific primers (J. VanderKelen, personal communication, March 2018). The strain specific PCR primers nearly successfully distinguished administered probiotic L. plantarum and P. acidilactici strains from feedendogenous bacteria while detection of $P$. pentosaceus remained confounded due to competition from feed-endogenous bacteria (Figure 6A, 6B, 6C).

\subsection{Survival and Transit Time of Probiotic Bacteria}

The detection of administered probiotic bacteria in the pen-combined feces of treated birds throughout the experiment suggests gastrointestinal tract survival and possible colonization of some birds in treated pens (Figure 6). Although fecal samples do not properly represent the entire gastrointestinal tract bacterial community, all probiotic bacteria could be detected in some fecal samples, demonstrating that the administered probiotics appeared to survive the gut of some birds (Stanley et al., 2014; Oakley et al., 
2014). Furthermore, all probiotic strains appeared to survive the acidic environment of the stomach as well as the secreted bile acids when entering the intestines 1-2 hours following probiotic administration (Figure 6), supporting the original probiotic transit time hypothesis.

A few days after probiotic administration ended, administered probiotic bacteria were detected more often in the control compared to treated birds, implying possible contamination of day 25 gut samples. On day 25 , the administered probiotic bacteria were observed more often in the control compared to treated birds, whereas in day 22 gut samples the administered probiotic bacteria were detected in treated birds only (with one P. acidilactici and four $P$. pentosaceus exceptions). Detecting $B$. subtilis more frequently in control than treated birds highly suggests a possible dirt or dust contamination, however, it's unclear whether the contamination occurred during the probiotic trial (most likely in the feed or water sources) or in laboratory when gut dissections were performed. Day 25 fecal results further indicates possible contamination of day 25 guts as well. The administered probiotic bacteria were no longer detected in the feces on day 25 (except $P$. pentosaceus) when all administered probiotic bacteria were previously detected in the feces during the probiotic trial, suggesting they were washed out of the gastrointestinal tract (Figure 6). Regardless, once administration stopped, the administered probiotic bacteria previously detected in day 22 lumen gut samples of treated birds were mostly washed out of the gastrointestinal tract (Table $10 \& 11$ ). This is consistent with other supplementation studies in which administered probiotic bacteria were flushed out of the gastrointestinal tract soon after probiotic administration was stopped (Fijan, 2014). 


\subsection{Probiotic Bacteria in Competition with Chicken Feed Bacteria}

The probable source of feed-endogenous bacteria was soybean meal, the only feed ingredient decreasing in amount from the starter to finisher diet (Table 1; Santosa at el., 2006). This decrease correlates with the decreased detection of both $P$. acidilactici and $L$. plantarum species from diet 1 to diet 2 (Table 5). Detection of feed-endogenous bacterial species (P. acidilactici, P. pentosaceus, and L. plantarum) in the chicken feed (Table 5) suggests competition for niches in the chicken gut may have occurred between these bacteria and the administered probiotic. $P$. pentosaceus species was only detected in diet 1 and once the diet switched at day 11 to diet 2 , the $P$. pentosaceus detected in the control birds decreased, which implies that the level of competition decreased after the change in diets (Figure 6).

Competitor species of probiotic bacteria could potentially inhibit survival and colonization for the administered probiotics. As previously mentioned, the disappearance of bacterial strains P. acidilactici and L. plantarum in the feces of treated birds from hour 6 until day 10 was most likely due to a low probiotic inoculum. The endogenous species of $P$. acidilactici and L. plantarum were detected in every pen, with only three exceptions (data not shown) supporting the presence of probiotic competitors. The existence of competition between endogenous and probiotic lactic acid bacteria was also supported by the feces qPCR data (Table 6) where both treatment and control birds had approximately similar concentrations of feed-endogenous bacterial cells. However, during chicken development the gut bacterial community matures from early colonizers to an adult stabilized community (Awad et al., 2016). This gut microbial community shift was seen where feed-endogenous bacterial concentrations decreased (both treated and control 
birds) from day 3 to day 7 (Table 6). As soon as the birds began drinking a higher probiotic inoculum in their water, the administered probiotic bacteria were detected in treated bird feces once again (Figure 6A \& 6B).

Cisek suggests the first inoculation of an organism's gut is most important for successful bacterial colonization of the digestive tract (Cisek et al., 2014). In this study, the feed-endogenous bacteria potentially inoculated the chicken gut first, limiting the chances for administered probiotic colonization. P. acidilactici, P. pentosaceus, and $L$. plantarum species were detected in the feeds given to the birds on arrival (one day prior to probiotic administration). The feed-endogenous $P$. acidilactici and $L$. plantarum were detected in day 1 gut samples (Table 7), suggesting immediate gut colonization by these bacteria after only one day of eating food, thus restricting administered probiotic colonization (Alloui et al., 2013). This could explain the minimal evidence for gut colonization by the administered probiotics.

\subsection{Probiotic Bacteria Gut Localization}

After 22 days of probiotic administration, there is little evidence of probiotic bacterial gut colonization in treated birds most likely due to competition with feedendogenous bacteria. However, all administered probiotics were detected more often in treated than control birds, suggesting a treatment effect where the administered probiotics appeared to survive the GI tract and compete for available niches in the gut. For example, P. pentosaceus was detected more often in treated birds, predominately in the ileal lumen and significantly in the cecal lumen $(\mathrm{p}=0.015)$. Similarly, both the administered $P$.

acidilactici and $L$. plantarum strains were detected in ileum and ceca lumen samples, but 
P. acidilactici was rarely detected at all and $L$. plantarum was detected in treated birds only (Table 10). The administered lactic acid bacteria (P. acidilactici, P. pentosaceus, and L. plantarum) were most commonly detected in the ceca gut compartment of broiler chickens, whereas the feed-endogenous $P$. acidilactici and L. plantarum were identified throughout the entire gut, primarily in the jejunal, ileal, and cecal lumen (Table 10). Although, administered probiotic colonization was unlikely, the feed-endogenous bacteria did show signs of colonization. Identification of feed-endogenous P. acidilactici and L. plantarum species in the ceca (lumen and mucosa) of every bird, with only four exceptions, suggests colonization (Table 10) (Donaldson et al., 2016). The related species from feed-endogenous bacteria of $P$. acidilactici and L. plantarum were identified to colonize the cecal mucosa, further supporting this gut compartment as the best location for the administered probiotic strains to colonize. Cecal colonization of feed-endogenous species $P$. acidilactici and L. plantarum most likely explains the lack of administered probiotic bacterial colonization. Furthermore, feed-endogenous bacteria were detected in the feces from all pens after probiotic administration ended (data not shown), implying colonization, while administered probiotic bacteria were no longer detectable (Figure 6). Administered probiotic colonization may have occurred in some treated birds, indicating the probiotic formula can colonize the chicken intestines. All four probiotic strains were detected in the digestive tract of only bird 2 from pen 2 (Table 10). Interestingly, the administered probiotic strain $P$. acidilactici was only detected in the guts of birds from pen 2, and P. acidilactici was detected throughout the experiment mostly in the feces of pen 2 (Figure 6), suggesting probiotic treatment variability. The birds of pen 2 possibly drank more probiotic water compared to other treatment pens, 
increasing the consumed probiotic inoculum. Thus, birds from pen 2 had the most probiotic bacterial detection in the fecal and gut samples, and the administered probiotics could have colonized these birds.

Unlike the lactic acid probiotic bacteria, B. subtilis displayed no noticeable sign of competition since this bacterial strain was consistently detected (in at least one pen) throughout the probiotic trial (Figure 6). B. subtilis was detected in the upper regions of the GI tract whereas the administered lactic acid bacteria were found in the lower gastrointestinal tract. B. subtilis spores can easily endure an acidic environment, allowing them to remain at detectable levels in the upper gut. It is not known if $B$. subtilis germinated or remained as spores, however, the spores eventually pass through the GI tract exciting in the feces where growth can occur in the presence of oxygen (Figure 6D).

The chickens involved in this study were healthy due to the experimental set up, which did not mimic the dirty overcrowded poultry industry living conditions. Thus, it's likely changes in gut microbiota composition and beneficial probiotic effects were not visible. The probiotic supplementation provided no obvious health benefits to the birds since there were no significant differences in body weight gain, feed intake, or feed conversion ratio. Even though the administered probiotic bacteria were detected in the chicken gut samples, (Figure 10) there was no significant difference in the gut microbiome between the treated and control birds (data not shown).

\subsection{Lumen and Mucosa Gut Microbiota}

The probiotic treatment had no effect on the gut microbiome, however, differences between the lumen and mucosa samples were identified in the foregut and disappeared in 
the hindgut. Although not significant, the jejunum ( $p=0.07$ ANOSIM) illustrated a bacterial community difference in lumen and mucosa samples in comparison to the ceca, while the ileum ( $p=0.67$ ANOSIM) had a less noticeable difference (Figure $7,8,9)$. The microbial composition is different between the lumen and mucosa in the upper gut, most likely due to different functional roles to maintain host health (Gong et al., 2002; Looft et al., 2014). The cecal gut compartment composed of two pouches is structurally unique compared to the long-convoluted tube of the small intestine. The structural differences of these gut compartments allow digested material to flow through the foregut quickly while the ceca retain the material for 12-20 hours (Awad et al., 2016). Therefore, it's possible that the bacterial community of the ceca lumen and mucosa are similar while the jejunum may have distinct bacterial communities between the lumen and mucosa.

\section{CONCLUSION}

Although there were no significant differences in body weight gain, feed intake, and feed conversion ratio, the administered bacterial strains appeared to survive the high acidity of the stomach, transfer through the gastrointestinal tract, and exit in the feces. A probiotic transit time to the feces of 1-2 hours was identified and probiotic lactic acid bacteria were predominately detected in the lower gastrointestinal tract. After probiotic administration ended, the probiotic strains were flushed out from the gastrointestinal tract.

All four administered probiotic bacteria were only detected in the guts of a few individual birds. Therefore, there was little evidence for colonization by the administered probiotic bacteria. Feed-endogenous lactic acid bacteria may have inhibited colonization by the administered probiotic bacteria. In addition, the probiotic inoculum concentration 
in water troughs was possibly lower than intended due to an unexpected probiotic formula cell die off over time. The low concentration of probiotic inoculum for over a week during chicken development possibly limited the chances of probiotic colonization. Lastly, no probiotic treatment health effects were observed, possibly due to the careful experimental set up of ideal housing conditions in which the birds were healthy and therefore, probiotic supplementation was not advantageous.

\subsection{Future Work}

Future studies are required to validate the conclusions from this initial research. Future investigators should make fresh probiotic water more frequently or increase the probiotic inoculum concentration to improve probiotic inoculation levels. In addition, future research might consider probiotic administration to chicks immediately after hatching. Performing early inoculation of treatment probiotics after the chicks hatch could possibly allow immediate gut colonization of the probiotic bacteria by reducing competition effects from feed-endogenous bacteria. Instead this study allowed one full day for the chicks to settle into their pens and the feed-endogenous bacteria inoculated the gut first. Also, alteration of the chicken housing experimental design to a more stressful or realistic poultry industry environment, where there is a need for animal feed supplementation, might demonstrate more noticeable signs of treatment probiotic gut colonization and beneficial health effects could be observed. 


\section{REFERENCES}

Adams, C. (2010). The probiotic paradox: Live and dead cells are biological response modifiers. Nutrition Research Review. 23.1: 37-46.

Aliakbarpour, H. R., M. Chamani, G. Rahimi, A. A. Sadeghi, D.Qujeq. (2012). The Bacillus subtilis and Lactic Acid Bacteria Probiotics Influences Intestinal Mucin Gene Expression, Histomorphology and Growth Performance in Broilers. Asian-Australasian Journal of Animal Sciences. 25.9: 1285-1293.

Alloui, M. N., W. Szczurek, F. Science. (2013). The usefulness of prebiotics and probiotics in modern poultry nutrition: a review. The Journal of National Research Institute of Animal Production. 13.1: 17-32.

Avon Animal Health. (2015). Towards Antibiotic Free Quality Farming. Retrieved from http://www.avonah.com/images/product/sgs_chick.png.

Awad, W. A.,E. Mann, M. Dzieciol, C. Hess, S. Schmitz-Esser, M. Wagner, M. Hess. (2016). Age-Related Differences in the Luminal and Mucosa Associated Gut Microbiome of Broiler Chickens and Shifts Associated with Campylobacter Jejuni Infection. Frontiers in Cellular and Infection Microbiology. 6: 154.

Barnes, E. M. (1972). The avian intestinal flora with particular reference to the possible ecological significance of the cecal anaerobic bacteria. American Journal of Clinical Nutrition. 25: 1475-1479.

Blajman, J. E., L. S. Frizzo, M. V. Zbrun, D. M Astesana, M. L. Fusari, L. P. Soto,... M. L. Sgnorini. (2014). Probiotics and broiler growth performance: a meta analysis of randomized controlled trials. British Poultry Science. 55: 483-494.

Carding, S., K. Verbeke, D. T. Vipond, B. M. Corfe, L. J. Owen. (2015). Dysbiosis of the gut microbiota in disease. Microbial Ecology in Health and Disease. 26: 26191.

Casula, G., S. M. Cutting. (2002). Bacillus Probiotics: Spore Germination in the Gastrointestinal Tract. Applied and Environmental Microbiology. 68.5: 23442352.

Chichlowski, M., J. Croom, B. W. McBride, G. B. Havenstein, M. D. Koci. (2007). Metabolic and physiological impact of probiotics or direct-fed-microbials on poultry: A brief review of current knowledge. International Journal of Poultry Science. 6: 694-704.

Cisek, A. A., M. Binek. (2014). Chicken intestinal micriobiota function with a special emphasis on the role of probiotic bacteria. Polish Journal of Veterinary Sciences.17.2: 385-394. 
Clermont, O., M. Lescat, C. L. O'Brien, D. M. Gordon, O. Tenaillon, E. Denamur. (2008). Evidence for a human-specific Escherichia coli clone. Environmental Microbiology. 10: 1000-10006.

Donaldson, G. P., S. M. Lee, S. K. Mazmanian. (2016). Gut Biogeography of the Bacterial Microbiota. Nature reviews. Microbiology. 14.1: 20-32.

Economou, V., P. Gousia. (2015). Agriculture and Food Animals as a Source of Antimicrobial-Resistant Bacteria." Infection and Drug Resistance. 8: 49-61.

Erkkilä, S., E. Petäjä. (2000). Screening of commercial meat starter cultures at low pH and in the presence of bile salts for potential probiotic use. Meat Science. 55.3: $297-300$.

Fooks, L. J., G. R. Gibson. (2002). Probiotics as modulators of the gut flora. The British Journal of Nutrition. 88.1: 39-49.

Fijan, S. (2014). Microorganisms with Claimed Probiotic Properties: An Overview of Recent Literature. International Journal of Environmental Research and Public Health.

Fuller, R. (1989). Probiotics in Man and Animals. Journal of Applied Bacteriology. 66.5: 365-378.

Gadde, U., S. T. Oh, S. T. Lee, E. Davis, N. Zimmerman, T. Rehberger, H. S. Lillehoj. (2017). The Effects of Direct-fed Microbial Supplementation, as an Alternative to Antibiotics, on Growth Performance, Intestinal Immune Status, and Epithelial Barrier Gene Expression in Broiler Chickens. Probiotics and Antimicrobial Proteins. 9.4: 397-405.

Gaggìa, F., P. Mattarelli, B. Biavati. (2010). Probiotics and prebiotics in animal feeding for safe food production. International Journal of Food Microbiology. 141: 1528.

Geier, M. S., V. A. Torok, G. E. Allison, K. Ophel-Keller, R. J. Hughes. (2009). Indigestible carbohydrates alter the intestinal microbiota but do not influence the performance of broiler chickens. Journal of Applied Microbiology. 106.5: 15401548 .

Gong, J., R. J. Forster, H. Yu, J. R. Chambers, P. M. Sabour, R. Wheatcroft, S. Chen. (2002). Diversity and phylogenetic analysis of bacteria in the mucosa of chicken ceca and comparison with bacteria in the cecal lumen. FEMS Microbiology Letters. 208.1: 1-7.

Gu, S. B., L. N. Zhao, Y. Wu, S. C. Li, J. R. Sun, J. F. Huang, D. D. Li. (2015). Potential probiotic attributes of a new strain of Bacillus coagulans CGMCC 9951 
isolated from healthy piglet feces. World Journal of Microbiology and Biotechnology. 31.6: 851-863.

Guan, L. L., K. E. Hagen, G. W. Tannock, D. R. Korver, G. M. Fasenko, G. E. Allison. (2003). Detection and Identification of Lactobacillus Species in Crops of Broilers of Different Ages by Using PCR-Denaturing Gradient Gel Electrophoresis and Amplified Ribosomal DNA Restriction Analysis. Applied and Environmental Microbiology. 69.11: 6750-6757.

Hughes, L., P. Hermans, K. Morgan. (2008). Risk factors for the use of prescription antibiotics on UK broiler farms. Journal of Antimicrobial Chemotherapy. 61.4: 947-952.

Lillehoj, H. S., K. W. Lee. (2012). Immune modulation of innate immunity as alternatives-to antibiotics strategies to mitigate the use of drugs in poultry production. Poultry Science. 91.6: 1286-1291.

Looft, T., H. K. Allen, B. L. Cantarel, U. Y. Levine, D. O. Bayles, D. P. Alt,...T. B. Stanton. (2014). Bacteria, Phages and Pigs: The Effects of in-Feed Antibiotics on the Microbiome at Different Gut Locations. The ISME Journal. 8.8: 1566-1576.

Makarova, K. S., A. Slesarev, Y. Wolf, A. Sorokin, B. Mirkin, E. V. Koonin, D. A. Mills. (2006). Comparative genomics of the lactic acid bacteria. Proceedings of the National Academy of Sciences of the United States of America. 103.42: 1561115616.

Mikulski, D., J. Jankowski, J. Naczmanski, M. Mikulska, V. Demey. (2012). Effects of dietary probiotic (Pediococcus acidilactici) supplementation on performance, nutrient digestibility, egg traits, egg yolk cholesterol, and fatty acid profile in laying hens. Poultry Science. 91.10: 2691-2700.

Mountzouris, K., P. Tsitrsikos, I. Palamidi, A. Arvaniti, M. Mohnl, G. Schatzmayr, K. Fegeros. (2010). Effects of probiotic inclusion levels in broiler nutrition on growth performance, nutrient digestibility, plasma immunoglobulins, and cecal microflora composition 1. Poultry Science. 89.1: 58-67.

The National Chicken Council. (2015). Making Sense of the New Federal Rules on Antibiotics in Chicken Production. Retrieved from https://www.chickencheck.in/blog/making-sense-of-new-federal-rules-on antibiotics-in-chicken-production/

Noohi, N., G. Ebrahimipour, M. Rohani, M. Talebi, M. R. Pourshafie. (2016). Evaluation of potential probiotic characteristics and antibacterial effects of strains of Pediococcus species isolated from broiler chickens. British Poultry Science. 57.3: $317-323$. 
Oakley, B. B., H. S. Lillehoj, M. H. Kogut, W. K. Kim, J. J. Maurer, A. Pedroso, ...N. A. Cox. (2014). The Chicken Gastrointestinal Microbiome. FEMS Microbiology Letters. 360.2: 100-112.

Papagianni, M., S. Anastasiadou. (2009). Pediocins: The bacteriocins of Pediococci. Sources, production, properties and applications. Microbial Cell Factories. 8.1: 3.

Pedroso, A. A., M. D. Lee. (2010). Probiotics - do the organisms need to be alive? The Poultry Informed Professional. 114.1: 1-7.

Qin, J., R. Li, J. Raes, M. Arumugam, K. S. Burgdorf, C. Manichanh, ... J. Wang. (2010). A Human Gut Microbial Gene Catalog Established by Metagenomic Sequencing. Nature. 464.7285: 59-65.

Ray, D., D. Kidane. (2016). Gut microbiota imbalance and base excision repair dynamics in colon cancer. Journal of Cancer. 7.11: 1421-1430.

Ricke, S. C., F. T. Jones. (2010). Perspectives on food safety issues of food animal derived foods. University of Arkansas Press, Fayetteville, AR. 289-305.

Santosa, S., E. Farnworth, P. J. Jones. (2006). Probiotics and Their Potential Health Claims. Nutrition Reviews. 64.6: 265-274.

Smirnov, A., E. Tako, P. Ferket, Z. Uni. (2006). Mucin gene expression and mucin content in the chicken intestinal goblet cells are affected by in ovo feeding of carbohydrates. Poultry Science. 85: 669-673.

Soccol, C. R., L. P. Vandenberghe, M. R. Spier, A. B. Medeiros, C. T. Yamaguishi, J. D. Lindner, ...V. Thomaz-Soccol. (2010). The potential of probiotics: a review. Food Technol Biotech (2010). The Potential of Probiotics: A Review. Food Technology and Biotechnology. 48.4: 413-434.

Stanley, D., R. J. Hughes, R. J. Moore. (2014). Microbiota of the Chicken Gastrointestinal Tract: Influence on Health, Productivity and Disease. Applied Microbiology and Biotechnology. 98.10: 4301-4310.

Sturkie, P. D. (1976). Alimentary Canal: Anatomy, Prehension, Deglutition, Feeding, Drinking, Passage of Ingesta, and Motility. Avian Physiology. Springer Advanced Texts in Life Sciences.185-195.

Tang, Y., Y. Wu, Z. Huang, W. Dong, Y. Deng, F. Wang, M. Li, J. Yuan. (2017). Administration of Probiotic Mixture DM\#1 Ameliorated 5-fluorouracil induced Intestinal Mucositis and Dysbiosis in Rats. Nutrition. 33: 96-104.

Tottey, W., D. Feria-Gervasio, N. Gaci, B. Laillet, E. Pujos, J. Martin, ...J. Brugère. (2017). Colonic Transit Time Is a Driven Force of the Gut Microbiota 
Composition and Metabolism: In Vitro Evidence. Journal of

Neurogastroenterology and Motility. 23.1: 124-134.

Turnbaugh, P. J., R. E. Ley, M. Hamady, C. M. Fraser-Liggett, R. Knight, J. I. Gordon. (2007). The Human Microbiome Project: A Strategy to Understand the Microbial Components of the Human Genetic and Metabolic Landscape and How They Contribute to Normal Physiology and Predisposition to Disease. Nature. 449.7164: 804.

Vila, B., E. Esteve-Garcia, J. Brufau. (2010). Probiotic micro-organisms: 100 years of innovation and efficacy; modes of action. Worlds Poultry Science Journal. 66.3: 369-380.

Walters W., E. R. Hyde, D. Berg-Lyons, G. Ackermann, G. Humphrey, A. Parada, ...R. Knight. (2015) Improved Bacterial 16S rRNA Gene (V4 and V4-5) and Fungal Internal Transcribed Spacer Marker Gene Primers for Microbial Community Surveys. mSystems. 1.1: e00009-15.

Williams, N. T. (2010). Probiotics. American Journal of Health-System Pharmacy. 67.6: 449-458. 